\title{
Ruhekern und Mitose. \\ Untersuchungen über die Beschaffenheit des Ruhekerns und über den Ursprung und das Schicksal des Kernfadens, mit besonderer Berücksichtigung der Wirkung der Fixierungs- flüssigkeiten.
}

Von

Dr. Koloman v. Tellyesniczky

Privatdocent an der Universität zu Budapest.

Hierzu Tafel XXIV-XXVIII.

\section{Inhaltsübersicht.}

I. Ruhekern.

1. Verhältnisse am lebenden Kern. Kar y o s o men.

2. Technisches, Fixation, Färbung.

3. Grosse Spermatogonien des Salamanders.

4. Kleine Spermatogonien des Salamanders.

5. Ruhekerne im allgemeinen.

\section{Mitose.}

Jrsprang und Schicksal des Kernfadens.

1. Einleitung.

2. Prophasen der gewöhnlichen Mitose der kleinen Spermatogonien.

3. Prophasen der Reduktionsmitose, "Spermatocyten" der Autoren, nach Einwirkung der F l e m m i n g schen Flüssigkeit.

4. Zerfall der Karyos omen.

5. Ursprung des Fadens bei der gewöhnlichen Mitose.

6. Ursprung des Fadens bei der Reduktionsmitose.

7. Erklärungsversuch der ${ }_{n}$ Synapsis. ${ }^{*}$

8. Bemerkungen über die Eikerne.

9. Bildung des Tochterkernes. Zerfall der Chromosomen; Ursprung der Karyosomen.

10. Nukleokrystallin.

11. Zusammenfassung und Schluss.

\section{Einleitung.}

Auch der Histologe, der den gegenwärtigen Strukturtheorien im Allgemeinen wenig Vertrauen entgegenbringt, gibt sich gewöhnlich dem Glauben hin, dass sie vielleicht doch etwas Wahrheit in sich schliessen. Mit dieser Auffassung schritt auch ich an eine 
erneute Untersuchung der Kernstrukturen; das Resultat war aber eine Enttäuschung.

Ich habe die Kritik der bisherigen Anschauungen über die Kernstrukturen vorausgeschickt, ${ }^{1}$ ) welche die gegenwärtige Erneuerung der Kernuntersuchungen motivieren. Meine Bemerkungen in jener Arbeit bezogen sich auf die Untersuchungen lebenden Materials und auf die Fixierungs-Methoden. Die dritte Frage, die der Färbungsmethoden, berührte ich nicht, da die Bedeutung dieser neben den oben erwähnten zwei Methoden vollkommen in den Hintergrund tritt. Das gefärbte Präparat bietet nichts anderes, als das ungefärbte, es macht nur die Untersuchung bequemer. Veränderungen der Strukturen kann die Fårbung nach der Fixierung nicht mehr bewirken, während wir zur Annahme von Veränderungen durch das Fixieren allen Grund haben. Daher hängt die Lösung der Strukturfragen in erster Reihe von den Untersuchungen lebenden Materials und von der Kritik der Fixierungsmethoden ab.

Auch diesmal vermeide ich die Berührung der Plasmastrukturen vollkommen, wie ich es auch in meiner vorausgegangenen Kritik getan habe. Plasma und Kern scheinen prinzipiell verschiedene Formationen zu sein, welche man nicht einfach vergleichen und unter einen Hut bringen darf, wie dies in den bisherigen Strukturtheorien allgemein und konsequent geschehen ist. Auch hat man auf dem Gebiete der Plasmastrukturen ausgedehntere Untersuchungen angestellt, als bezüglich der Kernstrukturen. Von jenen Plasmauntersuchungen besitzen auch einige in bestimmter Richtung rationelle Motivierung und ausgedehntere Begründung; aber auch bei diesen verrieten die Forscher ihre Einseitigkeit dadurch, dass sie durch schnelle und leichte Verallgemeinerung ihre Resultate alle ohne jeden Vorbehalt auch auf den Kern ausdehnten. Hier werden dann die Schwächen der Untersuchungen offenbar, hier erscheint die Befangenheit der Ansichten in vollem Maße. Gewisse Tatsachen, die mit dem Plasma in eine mehr oder weniger annehmbare Übereinstimmung gebracht werden konnten, verraten durch jene oberflächliche Verallgemeinerung, die sie auch auf den Kern ausdehnte, solort ihre Irrealität. Es scheint, dass

1) Zur Kritik der Kernstrukturen. Arch. f. mikr. Anatomie 1902, Bd. 60. 
den Strukturtheorien in erster Reihe die Kernverbältnisse zur Achillesferse werden.

In Bezug auf den ruhenden Zellkern haben wir bisher keine feststehenden Kenntnisse. Unser positives morphologisches Wissen beginnt erst, wenn der auch im Leben wahrnehmbare Kernfaden auftritt, wenn also der Kern als solcher schon zu existieren aufgehört hat. ${ }^{1}$ ) Die Erscheinungen vom Auftreten des Kernfadens bis zur Bildung des Tochterkernes können wir dann leicht verfolgen. Hier aber sinkt der Vorhang wieder und abermals stehen wir vor einem Rätsel. Gerade so, wie wir nicht wissen, woraus der Kernfaden seinen Ursprung genommen hat, gerade so ist es uns unbekannt, was aus ihm wird, in was sich der Tochterstern in dem Tochterkerne verwandelt.

Vom histologischen Standpunkte ist das Wesen des ruhenden Kernes eine morphologische Frage; eine solche kann aber nur durch Berücksichtigung der Entwicklung gelöst werden. Eine nähere Erkenntnis des ruhenden Kernes kann also in erster Reihe nur von denjenigen Untersuchungen erwartet werden, welche uns auch die Entwicklung des ruhenden Kernes in entsprechender Beleuchtung vor Augen führen. Wenn wir zur Kenntnis dessen gelangen, auf welche Weise aus den Chromosomen der ruhende Kern zustande kommt, so haben wir damit auch für die Beurteilung des ruhenden Kernes eine sichere Grundlage gewonnen; diese Frage wieder steht mit der Frage nach der Entwicklung des Kernfadens selbst in innigem Zusammenhange.

Hiernach umfasst meine vorliegende Untersuchung drei ihrem Wesen nach streng miteinander verbundene Erscheinungen: 1) die Verhältnisse der ruhenden Kerne überhaupt, 2) den Ursprung des mitotischen Fadens, 3) die Neubildung der ruhenden Kerne, d. h. das Schicksal der Chromosomen in den Tochterkernen.

1) Dieser Stand unserer heutigen Kenntnisse bewog B o ve ri zu dem Unternehmen (,Ergebnisse über die Konstitation der chromatischen Substanz der Kerne" 1904. Jena.), den Kernverhältnissen auf in di rektem Wege näher zu treten, durch Erwägungen der Tatsachen der Mitose, resp. durch die Verhältnisse der Chromosomen auf die Beschaffenheit der Ruhekerne zurückzuschliessen. Hier sei nur kurz bemerkt, dass meine direkten Untersuchungen zu diametral entgegengesetzten Ergebnissen mit den Konklusionen B overis führten, worauf ich an einer anderen Stelle zurückznkommen gedenke. 
Die erste Frage, die nach den Verhältnissen des ruhenden Kerns, ist bekanntlich oft untersucht worden; die Mängel dieser Untersuchungen habe ich in meiner vorausgeschickten Kritik beleuchtet; die zwei letzteren Fragen, die nach dem Ursprung und dem Schicksal des mitotischen Fadens, sind vollkommen unberührt. Da aber die erste Frage für sich allein isoliert, eigentlich nicht lösbar ist, so konnte auch das Misslingen dieser Untersuchungen nicht ausbleiben. Ein wirkliches Verständnis der Kernverhăltnisse hat zur Bedingung, das der Zusammenhang zwischen den drei erwähnten Erscheinungen klargestellt werde.

Will man den ruhenden Kern verstehen, so muss man die Verhältnisse der Entstehung des ruhenden Kernes, wie auch den Ursprung des Kernfadens kennen. Für sich isoliert würden diese Fragen ein Rătsel bleiben.

Die bisherigen Untersuchungen konnten, abgesehen von den Irrtümern, welche aus den Untersuchungen lebenden Materiales and aus den Fixierungen stammten, schon deshalb nicht zum Ziele führen, weil der grösste Teil derselben die verschiedensten Kuriositäten der Kerne behandelt, ohne den Zusammenhang der drei genannten Erscheinungen näher zu beachten. Es liegt aber im Wesen dieser Fragen, dass die Lösung nur dort zu hoffen ist, wo dieser Zusammenhang berücksichtigt wird; die vorliegende Arbeit "Ruhekern und Mitose" will in dieser Richtung zur Klärung der Frage beitragen.

\section{Ruhekern.}

1. Verbältnisse am lebenden Kern.

\section{$\mathrm{K}$ ar yos o men.}

Bekanntlich sind die Untersuchungen lebenden Materiales umständlich, und dazu nicht viel zeigend; das Präparat ist nicht aufbewahrbar; man muss in der Eile beobachten, zeichnen etc., lauter Gründe, weshalb sie neben der bequemen Untersuchung der schönen gefärbten fixierten Präparate in den Hintergrund gedrängt wurden. Ich untersuchte die Gewebe einfach in ibrer eigenen Flüssigkeit mit homogener Immersion, und zwar nur in hellen klaren Mittagsstunden. Ich war zufrieden, wenn es mir bei je einer Mittagsuntersuchung gelang, eine einzige gut beobachtete Zeichnung für meine Notizen zu gewinnen. Die Ergebnisse waren folgende: 
Die im Leben wahrnehmbaren Kerne besitzen alle ohne Ausnahme eine wasserklare Grundsubstanz, welche die Hauptmasse der meisten Kerne ausmacht. Diese kann zwar gegen das Plasma hin eine feine Grenzlinie besitzen, oft aber besitzt sie überhaupt keine selbständigen Konturen (Taf. XXIV, Fig. 5).

Der wasserklare Charakter der Grundsubstanz offenbart sich insbesondere an solchen grossen Kernen, in welchen ausser ein bis zwei runden Nukleolen kein anderer Bestandteil vorhanden ist, wie in den grossen Spermatogonien vom Salamander, oder in den Ei- und Ganglienzellen der Säugetiere. Oft scheint in diesen Fällen die klare Kugel des Kernes gleichsam in der trüben Umgebung, resp. im Plasma zu glänzen (Taf. XXIV, Fig. 5).

Die wasserklare Grundsubstanz ist auch bei denjenigen Kernen ebenso gut wahrnehmbar, wo man in diesen verschieden grosse, nicbt runde Körperchen findet (Taf. XXIV, Fig. 1-4).

Diese Körperchen kann man mit nichts anderem besser und kürzer charakterisieren, als gerade durch jene ihre negative Eigenschaft, dass sie nicht rund sind, denn gerade dies unterscheidet sie von den bereits genau bekannten selbständigen Teilen des Kernes, von den streng runden Nukleolen.

In Zeichnungen kann man diesen Unterschied kaum so gut wiedergeben, wie sie uns in Wirklichkeit erscheinen, wo wir immer leicht konstatieren können, dass diese Gebilde nicht so regelmässig runde Formationen sind, wie die gewöhnlichen Nukleolen. Auch der Unterschied in der Lichtbrechung der Nukleolen und dieser Körperchen ist unbeträchtlich. Wichtig ist, dass auch diese Körperchen scharfe begrenzte freie Ränder haben, d. h. dass sie auch vollkommen frei stehen, wie die Nukleolen in der Grundsubstanz.

Die Umrisse dieser Körperchen treten bei guter Beleuchtung in der wasserklaren Grundsubstanz des lebenden Kernes vollkommen klar hervor. Wer sich von diesem wichtigen Umstande überzeugen will, dem empfehle ich die Untersuchung des Darmepithels vom Triton, in dessen Kernen man acht bis zehn freistehende nicht runde Körperchen verhältnismässig leicht beobachten kann.

Wenn auch schon in diesen Fällen diese Körperchen von den wahren Nukleolen leicht $z u$ unterscheiden sind, so ist dies noch mehr der Fall in jenen Kernen, in welchen sie in Form 
mehr länglicher Stäbchen erscheinen. Solche Formationen sind auch in den Kernen des Tritondarm-Epithels aufzufinden, aber viel hăufiger kommen sie in den kleinen Spermatogonien des Salamanders vor, wo solche länglichen Körperchen oft vorwiegend sind (Taf. XXIV, Fig. 1, Taf. XXVI, Fig. 5, 6, 7).

Diese Formationen, welche ich $\mathrm{Karyos}$ amen oder $\mathrm{Nukle}$ os o m e n nennen werde, zeigen in bezug auf ibre Form und Zahl grosse Mannigfaltigkeit. Die Mannigfaltigkeit steht teils mit dem Typus des Kernes im Zusammenhang, teils aber auch mit den verschiedenen Zuständen desselben Kernes. Mit dem Beginne der Mitose erleiden sie auffallende Veränderungen, welche weiter unten beschrieben werden sollen.

Der grösste Teil der Kerne zeigt im Leben den eben beschriebenen Typus, d. h., sie zeigen in einer klaren Grundsubstanz mehrere, 6-8-10 nicht regelmässig runde Körperchen, die Karyosomen. Die andere Art der Kerne entspricht dem bekannten Typus, bei welchem im wasserklaren Kerne nur ein bis zwei regelmässig runde Nukleolen sichtbar sind. Zweiffellos bilden diese beiden Kernarten die grosse Mehrzahl der im Leben sichtbaren Kernbilder. Es gibt aber auch andere.

Ausser diesen beiden Arten von Kernen können wir nämlich gleichfalls auf Grund der Beobachtungen an lebendem Material noch zwei andere erwähnen. Die eine Art weicht nicht wesentlich von den eben beschriebenen $a b$; der Unterschied besteht nur darin, dass die in ibnen sichtbaren selbständigen Körperchen relativ klein und in grösserer Zahl vorhanden sind, so dass sie den Kern gleichmässiger erfüllen. Hierher gehören $u$. A. die bekannten verzweigten Riesenkerne der Spinndrüsenzellen der Raupen, deren kleine Körperchen auch im Leben deutlich sichtbar sind.

Im ersten Augenblicke würde man geneigt sein von diesen riesigen verzweigten Kernen $\mathrm{zu}$ glauben, dass sie, ebenso wie in bezug auf ihre Grösse und Gestalt, auch in bezug auf ihren mehr granulierten Charakter einen ganz speziellen Zustand repräsentieren; ich habe mich aber überzeugt, dass derselbe granulierte Charakter der Kerne auch in anderen normal gestalteten Kernen der lebenden Raupen gleichfalls deutlich wahrnehmbar ist (Taf. XXIV, Fig. 13). So ist dieser Zustand bei den Raupen eine normale Erscheinung und ist auch wie wir sehen werden bei anderen Tieren aufzufinden. Wichtig ist der Umstand, dass 
auch diese kleinen Formationen in der homogenen Grundsubstanz als isolierte Körperchen erscheinen und sie, wie es sich weiter unten noch berausstellen wird, den obigen freistehenden Karyosomen entsprechende Bildungen sind.

Endlich begegnen wir auch Kernen, von deren Struktur man sich auf Grund der Untersuchungen im lebenden Zustande kein deutliches Bild schaffen kann, und so kann auch von einer getreuen Abbildung derselben keine Rede sein. Der Kern erscheint in diesen Fällen trübe und unklar; wir glauben in ihm bald Flecken, bald Streifen zu sehen, doch sind wir nicht imstande das Bild festzuhalten. Solche Kerne habe ich aus der Lunge und dem Mesenterium von Triton gezeichnet (Taf. XXIV, Fig. 16-19). Diese Bilder sind aber aus dem eben erwahnten Grunde nicht naturgetreu. Der aus der Lunge gezeichnete Kern gehört wahrscheinlich einer Epithelzelle an. Trotzdem scheint es, dass die so gearteten, im Leben so unbestimmte Verhältnisse zeigenden Kerne hauptsächlich auf Rechnung der Bindegewebszellen zu schreiben sind.

Die im lebenden Zustande untersuchbaren Kerne können also in vier Gruppen gebracht werden. In die erste Gruppe gehören die bisher gewöhnlich beschriebenen wasserklaren Kerne mit einigen regelmässig runden $\mathrm{Nukleolen;}$ in die andere grössere Gruppe diejenigen, in deren wasserlslarer Grundsubstanz mehrere (acht bis zehn) isolierte, unregelmässig geformte, oft längliche Körperchen, die Karyosomen, vorkommen. Die Kerne der dritten Art sind die, deren Inneres durch viele kleine Karyosomen verhältnismässig dicht und gleichmässig ausgefüllt wird. Endlich müssen wir noch eine vierte Gruppe in Gestalt jener Kerne aufstellen, deren Formationen im lebenden Zustande nicht entschieden werden können.

Die ausführlichere Untersuchung der lebenden Verhältnisse ist noch eine Aufgabe der Zukunft. Auf Grund des vorher gesagten ist es aber zweifellos, dass der Hauptteil des Kerns im Leben als klarer Flüssigkeitstropfen erscheint, in welchem sich isoliert stehende Körperchen, und zwar nicht nur die Nukleolen, sondern auch sehr verbreitete Körperchen von ganz anderer Art, die Karyosomen, befinden.

Unter diesen verschiedenen Kernen musste ich nun die Objekte zu meinen weiteren Untersuchungen auswählen. Die 
Wahl wurde dadurch erschwert, dass für mein Ziel, den $\mathrm{Zu}$ sammenhang des Ruhekerns mit der Mitose zu erforschen, nur solche Kerne herangezogen werden konnten, deren Mitosen uns in grossen Mengen zur Verfügung stehen. Für diese Untersuchungen sind die Hoden des Salamanders besonders geeignet.

Die Schwierigkeiten erreichen mit dem Beginn der Mitose ihren Höhepunkt. Die Bilder lebender Zellen versagen hier vollkommen.

Was sich im Innern des Kernes abspielt, was für Umwälzungen in der Werkstatt des Kernes sich während dieser Zeit des Wachstums bis zum Auftreten des Fadens vollziehen, bleibt für die Beobachtung lebenden Materials aller Wahrscheinlichkeit nach für immer verschlossen. Hier muss man für jetzt notgedrungen auf die Untersuchungen am Lebenden verzichten und sich ohne jeden sichern Halt in das Labyrinth der fixierten Bilder begeben. Deswegen ist es notwendig, zuerst die Methoden zu prüfen.

2. Technik (Fixation, Färbung).

Was und wieviel in den fixierten Bildern der Wahrheit entspricht, kann immer nur nach näheren Untersuchungen und kritischem Überlegen entschieden werden. Ausser den Untersuchungen am Lebenden muss man noch alle Möglichkeiten der Entstehungen von Kunstprodukten in Betracht ziehen. Die Ursachen der Entstehung von Kunstprodukten können in zwei Gruppen geteilt werden.

Zuerst müssen wir, wie auch am meisten erwähnt wird, Gerinnungs- und Făllungserscheinungen berücksichtigen, welche zu neuen Formationen, zur Bildung gewisser Strukturen führen können. Zweitens können bei nichtfällenden Mitteln und längerem Verweilen der lebenden Substanz in denselben, insbesondere, wenn die Flüssigkeit noch als hypotonisch gelten darf, Quellungs- und Lösungserscheinungen angenommen werden; diese können also zum Verschwinden von Bestandteilen, bezw. von Formationen führen.

Diese einfachen Gesichtspunkte wären aber nur dann unmittelbar anwendbar, wenn alle Teile der zu fixierenden Objekte gleichzeitig mit der Fixierungsflüssigkeit in Berührung kämen. Der Umstand aber, dass die Fixierungsflüssigkeiten nur auf dem Wege der Diffusion einwirken können, kompliziert die 
Verhältnisse ausserordentlich. Die Wirkung der FixierungsFlüssigkeiten ist an der Peripherie total verschieden als im Zentrum der Objekte und kommt in den verschiedensten Abstufungen zur Geltung. Gerade die Beurteilung dieser verschiedenen Wirkungen bietet, wie wir sehen werden, die grössten Schwierigkeiten.

Natürlich untersuchte auch ich die der allgemeinen Meinung entsprechenden „schönen“ Bilder. Vergessen wir aber nicht, dass auch die ,schönsten" Bilder nichts anderes bedeuten, als dass das Plasma und der Kern in bezug auf seine Masse und Form genügend gut erhalten ist. Was und wieviel in diesen „gut" konservierten Bildern innerhalb des Rahmens dieser schönen Formen der Wirklichkeit entspricht, bildet eben die offene Frage, deren Beantwortung zu erstreben ist.

Die vorliegenden Untersuchungen habe ich besonders mit zwei ,guten" Fixierungsmitteln angestellt: mit der stärkeren Flemmingschen Lösung und mit einer Mischung von 3 grm. Kali bichromicum und 5 ccm Essigsäure auf 100 Teile Wasser (100 Teile $3 \%$ iges Kalibichr. und $5 \mathrm{Cm}^{3}$ Essigsäure).

Die Flemmingsche Flüssigkeit ist bei der Stückfixation nur in der stärkeren Kombination brauchbar, denn die Diffusionsverhältnisse lassen auch bei dieser noch viel zu wünschen übrig. Die Erklärung ihrer Wirkung ist die verfänglichste Fixationsfrage, aber - wie wir sehen werden - auch die interessanteste. Das chameleonartig wechselnde Bild, das in den mit Flemmingscher Flüssigkeit fixierten Schnitten ein- und dasselbe Stadium der Mitose zeigt, ist an und für sich ganz unverständlich. Das Fixiermittel, welches durch parallele Vergleichung mit der Flemmingschen Flüssigkeit zur Überwindung der Schwierigkeiten diente, war die Kalibichromicum-Essigsäure-Mischung.

In meinen früheren Mitteilungen hob ich hervor, ${ }^{1}$ ) dass sowohl die Osmium, wie auch die Kaliumbichromat enthaltenden Flüssigkeiten die unversehrte, volle Konservierung der Masse des Plasmas und des Kernes bewerkstelligen, dass hingegen nach Einwirken anderer Fixationsmittel fast ohne Ausnahme sowohl im Plasma als auch im Kerne auffallende Mängel konstatiert

1) Fixation im Lichte neuerer Forschungen. Ergebnisse d. Anat. u. Entw., Bd. XI, 1901 und Encyklopädie d. mikr. Technik. Fixation. 
werden können. Daher war ich genötigt, bei den osmium- und kaliumbichromat $f \mathrm{r}$ e i e $\mathrm{n}$ Fixationsmitteln unbekannte Auslösungen anzunehmen. Erst vor kurzer Zeit kam ich darauf, dass bei dieser Erscheinung besonders die Lösung der fettartigen Substanzen eine wichtige Rolle spielt.

Aus der Vergleichung der Wirkung beider Flüssigkeiten wurde es nämlich klar, dass die vollen Bilder des Plasmas und des Kernes bei Einwirkung von Osmium- und Kaliumbichromicumgemischen in der unlöslichen Konservierung gewisser fettartiger Substanzen ihre Erklärung finden.

Die parallelen vollen Zellenbilder der Osmium- und Kaliumbichromicum-gemische stimmen mit derjenigen gemeinsamen Eigentümlichkeit der beiden Substanzen überein, dass sie die fettartigen Stoffe konservieren. Das Kaliumbichromat wurde gerade durch das Konservieren des Myelins wertvoll; die Konservierung der Fette durch Osmiumsäure ist bekannt. Bei den meisten andern Fixationsmitteln werden durch die Nachbehandlung sămtliche Fette ausgelöst.

Es ist interessant, dass auch die Färbungen mit diesen Verhältnissen parallele Erscheinungen zeigen. Bei den Fixationsmitteln, wo diese Lösung der fettartigen Substanzen ohne weiteres zustande kommt, ist auch die Färbbarkeit gut und leicht. Bei den mit Osmium und Kaliumbichromat fixierten Schnitten ist auch die Färbung erschwert, was eben mit der unlöslichen Konservierung der fettartigen Substanzen in Zusammenhang steht.

Es kann auch direkt bewiesen werden, dass die fettartigen Substanzen die Färbungen nicht nur im Leben, sondern auch in den fixierten Präparaten auffallend beeinflussen; hier möchte ich aber diese Frage nur insoweit berühren, als ich mir in den Zellen diese unsichtbaren fettartigen Substanzen nicht in oberflächlicher, sondern in diffuser Verteilung vorstelle. Die Annahme der von vielen Seiten erwähnten oberflachlichen Verteilung nach Art einer Membran wird weder von den Fixationsnoch von den Fărbungsverhältnissen unterstützt; die Bilder sprechen vielmehr für eine diffuse Verteilung dieser Substanzen.

Die Färbung ist zwar nach Anwendung von osmium oder kaliumbichromathältigen Flüssigkeiten im Vergleich zu den anderen Fixationsmitteln auffallend erschwert, doch gelangen wir bekannt- 
Jich mit gewissen Färbungen auch bei diesen zum Ziele. Bei beiden wurde das Safranin besonders empfohlen und es liefert auch in der Tat ,schöne" Bilder. Es stellte sich aber bald heraus, dass bei derartigen Untersuchungen, wie die vorliegenden, die Safraninfürbung fast ganz wertlos ist; es scheint, dass die roten Färbungen zu minutiöseren Untersuchungen ganz unbrauchbar sind. Der Unterschied zwischen der intensivsten SafraninFarbung und irgend einer Hämatoxylin-Färbung erwies sich so gross, dass gewisse, mit Hämatoxylin schon in den Anfangsstadien der Mitose erkennbare feine Formationen mit Rotfărbung auch nicht einmal in späteren Stadien besonders überzeugend konstatiert werden konnten.

Die Brauchbarkeit dieser zweierlei Färbungen wird übrigens auch von dem Umstande beeinflusst, dass bei künstlicher Beleuchtung die Rotfärbung vollkommen unbrauchbar wird, die schwarzen und blauen Farben dagegen auch bei solcher Beleuchtung ausserordentlich scharfe Bilder liefern.

Von meinen mit den erwähnten beiden Flüssigkeiten fixierten Präparaten erwiesen sich besonders jene als brauchbar und wertvoll, die mit einer Art der Weigertschen Markscheiden-Färbung gefärbt waren. (Beizen der Schnitte in gesättigtem Cupr. acet. 24 Stunden, Auswaschen in dest. Wasser, Färbung in $1 \%$ iger Hämatoxylin-Lösung 24 Stunden, Differenzierung in verdünnter Weigertscher Differenzierungsflüssigkeit). Bei der KaliessigsäureFixation erwies sich auch eine intensive Färbung mit gewöhnlichem Alaun-Hämatoxylin zur Erkennung der feinsten Details vorteilhaft.

Die Färbungen leisten natürlich, was die Sichtbarkeit und Beobachtungsmöglichkeit der Einzelheiten anbelangt, einen grossen Dienst, können aber dafür zu grossen Irrtümern führen, wenn sie etwa als Grundlage der Beurteilung genommen werden sollten, welches verhängnisvolle Verfahren seit den altesten Zeiten immer wieder auftaucht.

In neuerer Zeit hätte man doch hoffen können, den Übertreibungen dieser Richtungen nicht mehr zu begegnen; ich hätte auch diese Frage unberührt gelassen, wenn nicht unlängst eine Arbeit erschienen wäre, deren Untersuchungen fast ausschliesslich auf den problematischen Grundlagen der ,Rotblau"-Färbungen aufgebaut sind. 
R o h d $\mathrm{e}^{1}$ ) geht einerseits von den auf den, ,Rotblau'-Farbungen beruhenden Irrtümern $A$ u erbachs aus, nach welchen z. B. für männliche Kerne die Blaufärbung, für weibliche die Rotfärbung eine charakteristische Reaktion gäbe; andererseits glaubt er, gestützt auf Malfattis Untersuchungen, in der grünen Farbe das reine Nukleïn, in der violetten den phosphorarmen, in der roten den sehr phosphorarmen Kern zu erkennen.

Diese Deutungen der Farben fungieren in Rohdes Untersuchungen nicht nur als gewisse Möglichkeiten, sondern seine ganze ausgedehnte Untersuchung ist durchweg auf diesen „Rotblau"Färbungen gleichsam als auf den sichersten chemischen Reaktionen aufgebaut. Dass schon Fischer einzelne physikalische Faktoren der „Rotblau"-Färbungen mitteilt, welche eine viel verständlichere und einfachere Erklärung der zwei Färbungen geben, davon nahm Rohde keine Kenntnis. Auf diese Weise wuchs sich Auerbachs Irrtum über die Färbung der Kerne in Rohdes Händen $\mathrm{zu}$ einem verwirrenden Chaos aus.

Bei derartigen Untersuchungen, bei welchen das Wesen selbst der Methoden unbekannt ist, sollte nicht nur das Aufstellen jeder kühnen Theorie vermieden, sondern überhaupt jede Folgerung nur mit grösster Vorsicht gezogen werden.

Vor solchen aus den Färbungen gezogenen Schlüssen können uns auch alltägliche Erfahrungen warnen; so kann die Rotblau-Farbung eines gewöhnlichen Hodenpräparates uns schon von der Unrichtigkeit solcher Annahmen überzeugen. Oft erhalten wir Präparate, bei welchen die Kerne der Spermatiden und der reifen Spermatozoen blau, die anderen grösseren Kerne desselben Hocienkanals rot gefärbt sind, in welchem Falle man schwerlich von männlichen und weiblichen Kernen sprechen kann. $\mathrm{F}$ is $\mathrm{ch} \mathrm{e} \mathrm{r}^{2}$ ), dessen Untersuchungen $\mathrm{Rh}$ o d e nicht einmal erwähnt, weist doch klar nach, dass diese beiden Färbungen mit den verschiedenen Dichtigkeitsverhältnissen des "Chromatins" zusammenhängen, was tatsächlich auch durch andere histologische Erfabrungen bewiesen wird. So ist es auch eine ganz regelmässige Erscheinung, dass kleine Kerne, die sich blau färben, nach ihrem Anwachsen erythrophil werden. Rhode will in diesen

1) Untersuchungen über den Bau der Zelle. I. Kernkörperchen. Zeitschrift für wissenschaftliche Zoologie, 1903.

2) Fixierung, Färbung und Bau des Protoplasmas. Jena 1899. 
Fällen die Abnahme des Phosphors konstatieren, eine interessante Erklärung, der ich mich aber nicht anschliessen könnte, ebensowenig wie wohl die meisten anderen Autoren.

In meinen Untersuchungen spielen die Rotblau-Färbungen keine Rolle. Mein Ziel war immer eine dunkle intensive Hämatoxylin-Farbung, mit welcher man am sichersten, auch in den dünnsten Schnitten, die feinsten Formationen zur klaren Wahrnehmbarkeit bringen kann.

Auf Färbungsreaktionen kann man überhaupt nicht viel bauen, denn das Wesen der heutigen mikroskopischen Distinktionen stelit am Ende noch immer auf morphologischer Grundlage. Ich will aber deshalb die Färbungen selbst in dieser Richtung nicht für vollkommen wertlos halten, denn sie können, mit Vorsicht angewendet, in dem leider sehr engen Gebiete der histologischen Argumentation noch immer Platz finden.

\section{Grosse Spermatogonien vom Salamander.}

Die grossen Spermatogonien des Salamanders sind zur Untersuchung sowohl des ruhenden Kernes als auch der Teilungen ein vorteilhaftes Material. Ihr Nachteil besteht nur darin, dass sie im Vergleiche zu den übrigen Zellen des Hodens in geringer Zahl vorhanden sind.

Dieser Umstand beförderte auch die Annahme der Degeneration dieser Zellen; es können aber im Verhältnis zu ihrer Zahl besonders zu Anfange des Frühjahrs genug Mitosen beobachtet werden.

Da aber seit jeher besonders die zu gewissen Zeiten wahrnehmbaren polymorphen Gestalten dieser Kerne die Aufmerksamkeit der Autoren fesselten, und die Mitosen nicht beschrieben wurden, schien die Annahme einer Degeneration nicht vollständig aus der Luft gegriffen. Heutzutage ist aber diese Annahme ein überwundener Standpunkt.

Auch Meves hebt hervor, in diesen Zellen nie Degenerationserscheinungen gefunden zu haben. Wenn diese Riesenzellen wirklich degenerieren würden, so müssten wir dies Schritt für Schritt bis zum gänzlichen Verschwinden der Zellen verfolgen können, was jedoch nicht der Fall ist. Auch der einzige Grund für die Annahme der Degeneration, die polymorphe Gestaltung, wurde durch die Untersuchungen $\mathrm{N}$ us s b a m s (Über Kern- und Zellteilung, Arch. f. mikr. Anat., Bd. LIX, 1902) vollkommen verständlich, welche bewiesen, dass die polymorphe Gestaltung auch ein der Mitose vorangehendes Stadium des Kernes vorstellen kann.

Es kann nicht geleugnet werden, dass diese Erscheinung ohne die Kenntnis dieser Tatsache nicht gehörig verständlich war, denn, wie bekannt,

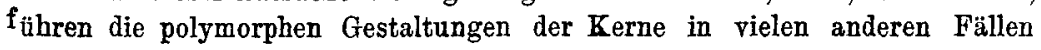


zweifellos zur Degeneration. Im Embryo erscheinen die grossen Spermatogonien zuerst, und von ihnen stammen die übrigen Generationen der Spermatognese ab.

Der Übergang von den grossen Spermatogonien zu den kleinen vollzieht sich in so präziser Bilderreihe, mit solcher stufenweisen Verkleinerung der Zellen, mit so fortwährender Einschaltung von Mitosen, dass über die Bedeutung des Vorganges kein $Z$ weifel bestehen kann. Auch die Benennung Ursamen-Zellen ist empfehlenswert, weil sie auch auf den Umstand hinweist, dass diese Zellen im Salamanderhoden eigentlich einen embryonalen Zustand darstellen; bei den höheren Wirbeltieren spieien im erwachsenen Zustande nur deren Abkömmlinge, die Spermatogonien, eine Rolle, die den kleinen Spermatogonien des Salamanders entsprechen.

Es war notwendig, diese Tatsachen zu erwähnen, damit niemand den normalen Charakter dieser Zellen bezweifle. Zur Untersuchung des ruhenden Kernes liefern sie ein ausgezeichnetes Material; durch die Bemerkungen von Meves, die sich auf diese Kerne beziehen, werden sie auch zur Charakterisierung der bisherigen Anschauungen geeignet.

Meves beschreibt in einer seiner Arbeiten ${ }^{1}$ ) diese Kerne und gibt von ihnen ganz richtig an, dass sie nur Chromatinbröckel aufweisen, ohne ausgesprochene Struktur. In einer späteren Arbeit ${ }^{2}$ ) aussert er sich dahin, dass einzelne von diesen Zellen, die in den grösseren Lappen tiefer liegen, ihrem Aussehen nach den Strukturanschauungen besser entsprechen und eher die Wahrheit vorstellen sollen.

Wie wir sehen werden, findet das verschiedene Aussehen der oberflächlich und der tiefliegenden Kerne seinen Grund in den verschiedenen Wirkungen der Flüssigkeiten an der Oberfläche und in den zentralen Teilen des Objektes. Meves fand in den grossen Spermatogonien zuerst deshalb keine Strukturen, weil sie, im kleinsten Lappen des Hodens gelegen, fast ausschliesslich die oberflăchliche Wirkung der Flemmingschen Flüssigkeit zeigen, welche in diesem Falle, wie wir sehen werden, gerade die wirklichen Verbältnisse konserviert. Die tieferliegenden Kerne dagegen, auf welche das Osmium nicht einwirken konnte, und in welchen in erster Reihe durch die Essig- und Chromsäure Niederschläge entstanden sind,

1) Über amitotische Kernteilung in den Spermatogonien des Salamanders etc. Anat. Anz., Bd. VI, 1891.

2) Über die Entwicklung der männlichen Geschlechtszellen von Salamandra maculosa. Arch. f. mikr. Anat., Bd. 48, 1897. 
liefern eben deswegen besser färbbare und den bisherigen Strukturanschauungen besser entsprechende Bilder.

Wir müssen aber gleich erwähnen, dass auch diese Bilder nur wegen Mangel eines besseren Materials, als tatsächlich bestehenden Strukturen entsprechende angesehen werden.

Meves teilt auch insofern Flemmings Ansichten, als er das Fehlen der Strukturen in den Osmiumbildern in der Weise zu erklären glaubt, dass diese durch die entstehenden Niederschläge verdeckt werden; da nun aber die Osmiumsäure an und für sich kein Eiweissfäller ist, kann diese Erklärung für die Osmiumbilder nicht zutreffen. Es sei noch bemerkt, dass bei derartigen Untersuchungen, wie die vorliegenden, eigentlich nur ein kleiner Teil des Kerns untersucht werden kann; dickere Schnitte, in welchen gewisse Formationen einander verdecken könnten, sind für diese Untersuchungen unbrauchbar.

Meine Befunde an diesen grossen Kernen ergaben folgendes:

Die Kerne der grossen Spermatogonien sind im Leben wasserklar, oft findet man in ihnen nur ein bis zwei Nukleolen, ausnahmsweise aber auch mehrere ('Taf. XXIV, Fig. 5, 9, 10).

Nach Einwirkung reiner Osmiumsäure, wie auch bei der peripherischen Wirkung der Flemmingschen Flüssigkeit, entsprechen die Kerne sowohl bezüglich ihrer Form, als auch ihrer Konturen, ferner im Verhalten ihrer Grundsubstanz und im Aussehen der Nukleolen, also in allem Wesentlichen, vollkommen den Bildern frisch untersuchter Kerne (Taf. XXV, Fig. 11a, 12a).

Diese Übereinstimmung ist deshalb wichtig, weil sie mit der Tatsache vereinbar ist, dass das Osmium das Eiweiss nicht fällt und daher auch keine strukturähnlichen Niederschläge erzeugen kann. So kann man bei den Osmiumbildern nicht annehmen, dass hier Niederschläge gewisse Strukturen verhüllen könnten.

Ganz andere Bilder liefern diese Kerne, wenn sie in fällenden Reagentien fixiert werden. Bei diesen erscheinen dann, wie auch bei der einfachen Essigsäure-Reaktion, parallel mit den Fällungen-Formationen Bilder, die von dem Verhalten beim Lebenden abweichen (Taf. XXIV. Fig. 6, 7, 12, 15; Taf. XXV, Fig. 1, 2, 3, 4, 5).

Das Abweichen dieser Bilder von dem lebenden Zustande besteht hauptsächlich darin, dass die vorher homogene, klare Grundsubstanz schollig, körnig erscheint, und der ganze Kern eine 
scharfe Kontur aufweist; auf diese Weise entstehen die Strukturen und die Kernmembran.

Die durch diese Fällungen entstandene Formation besteht zwar nur aus unregelmässigen Körnchen und Schollen, aber auch diese galten - wie wir erwähnten - in Ermangelung regelmässigerer Formationen als Strukturen.

Die gefällten Körnchen und Schollen entsprachen deshalb besser den strukturellen Auffassungen, weil sie auch besser färbbar sind, als die homogenen Osmiumbilder. Solche Körnchen und Schollen treten auch bei der Anwendung der Flemmingschen Flüssigkeit auf, aber nur in den tieferen Teilen, auf welche das Osmium nicht mehr einwirken kann.

Wir würden aber sehr irren, wenn wir glaubten, dass alle diese Bilder irgendwelche Strukturen vorstellen. Das Wesen dieser Formationen zeigt Taf. XXV, Fig. 5 a u. b, von welchen a einen grobscholligen, $b$ einen feinkörnigen Charakter zeigt. Der Charakter der ausgefällten Grundsubstanz schwankt zwischen diesen beiden, aus zwei Kerne gezeichneten Bildern.

In den Kernen der Spermatogonien ist weder an den Osmiumbildern, noch an den auf andere Weise fixierten, noch aber an den Bildern lebender Kerne etwas zu finden, was zur Annahme irgendwelcher Strukturen berechtigen könnte.

Sollten vielleicht die Strukturen durch die Einwirkung des nichtfällenden Osmiums verschwinden, ebenso wie bei den fällenden Behandlungen? Dies erscheint nicht nur unwahrscheinlich, sondern das gänzliche Fehlen jeder Struktur bei entgegengesetzt wirkenden Reagentien liefert das schwerste Argument gegen die Realität der Strukturen.

Aber es ist noch ein anderer mehr überzeugender Umstand vorhanden, dessen Bedeutung nicht genug betont werden kann.

Bei den fällenden und auch „schöne ${ }^{*}$ Bilder liefernden Fixationen können wir nämlich dessen vollkommen sicher sein, dass, wenn schon im Leben eine Formation vorhanden gewesen wäre, diese durch die Fixation eigentlich noch viel besser sichtbar werden müsste. Dazu kommt noch, dass durch die Färbungen die schon im Leben geformten Bestandteile der Kerne noch schärfer hervortreten würden. Von einem Verschwinden der Strukturen kann also in diesen Präparaten gar keine Rede sein. 
Die Körnchen und Schollen, welche die Kerne dieser Zellen, nach Behandlung mit Fallungsmitteln ausfüllen, sind nichts anderes als Fällungserscheinungen, die nach dem verschiedenen Zustande der Kerne bald feinkörnig, bald gröber, schollig erscheinen. Die Bilder sind ja auch den gewöhnlichen Fällungsformen des Eiweisses ähnlich.

Wir haben keinen Grund anzunehmen, dass diese Fällungen etwas vor unseren Blicken verdecken. Wenn zwischen diesen sich schwach färbbaren Körnchen (erythrophile Substanz der Autoren) irgendwelche beliebig feine (zyanophile) Bildungen sich befänden, so müssten ja diese durch die Färbungen ganz sicher sichtbar werden, was jedoch nicht der Fall ist.

Das einfache klare Aussehen der grossen Spermatogonienkerne, die wie Flüssigkeitstropfen erscheinen, ohne Membran, nur mit Nukleolen ${ }^{1}$ ), steht nicht nur mit den Strukturanschauungen im schroffen Widerspruch, sondern macht auch die Măngel des Begriffes „Chromatin“ sehr füblbar.

Es taucht sofort die Frage auf, wo sich eigentlich in diesen Kernen die dem "Chromatin" entsprechende Substanz befinde? Aus dem Obigen wird schon ersichtlich, dass diese Kerne keine Chromatinfärbungen geben und bei "Rotblau“-Färbungen der ganze Kern, die Nukleolen ausgenommen, nur eine rote Fărbung annimmt. So besteht der ganze Kern ausser den Nukleolen nur aus der erythrophilen Substanz der Autoren.

Gibt es also in diesen Kernen weder „Strukturen" noch „Chromatin"? Diese Frage wird am Ende meiner Arbeit ihre Antwort finden.

\section{Kleine Spermatogonien des Salamanders.}

Bisher war von Kernen von aussergewöhnlicher Grösse die Rede, die in bezug auf ihren Charakter den Kernen der Eizellen und Ganglienzellen ähnlich sind. Wir wissen nun aber, dass sich

1) Dass der Kern flüssig ist, ergibt sich schon aus der alltäglichen Erfahrung, dass er nach Beschädigungen genau so wie Plasma zerfliesst, was man bei grösseren Kernen auch direkt unter dem Mikroskope beobachten kann. Eine nähere Begründung des flüssigen Zustandes des Kernes und des Fehlens einer besonderen Kernmembran gab Dr. E. Albrecht. Experimentelle Untersuchungen über die Kernmembran. Beitr. z. path. Anat., Festschr. f. Bollinger 1903. 
diese grossen Kerne der Spermatogonien mit Einschaltung von Mitosen fortwährend verkleinern, bis sie endlıch die Grösse der kleinen Spermatogonien erreichen.

Parallel mit dieser Verkleinerung tritt eine andere Erscheinung auf, welche mit der Volums-Abnahme des Kernes in direktem Zusammenhange zu sein scheint; während nämlich die Kerne kleiner werden und sich dem Zustande der kleinen Spermatogonienkerne mehr und mehr năhern, erscheinen in ihnen neue Formationen: die auch im Leben in vielen Kernen sichtbaren, von mir oben Karyosomen genannten Gebilde.

Taf. XXIV, Fig. 1 stellt einen frischuntersuchten kleinen Spermatogonienkern vor, in welchem, wie wir sehen, die Karyosomen gut wahrnehmbar sind. Diese können aber auch in den fixierten Präparaten bequem untersucht werden (Taf. XXVI, Fig. 5, 6, 7), wieder ein Beweis dafür, dass in dem durch Gerinnen "gut" fixierten Präparate die lebenden Formationen nicht nur nicht verdeckt werden, sondern erst wirklich gut sichtbar erscheinen. Die Karyosomen erscheinen in den fixierten Präparaten geradeso wie im Leben. Bei reiner Osmiumwirkung, oder bei oberflächlichen Wirkung der Flemmingschen Flüssigkeit (Taf. XXVI, Fig. 5) befinden sich die Karyosomen, wie im frischen Kern, in eine homogene Grundsubstanz eingebettet. Bei fällenden Fixationen, oder in den tieferen Schichten bei Anwendung der Flemmingschen Flüssigkeit (Taf. XXVI, Fig. 6, 7) sind sie aber schon mit Körnchen und Schollen umgeben. Wie auch aus den Abbildungen ersichtlich ist, stören die körnigen Fällungen der Kernflüssigkeit keineswegs die gute Sichtbarkeit der Karyosomen.

In den kleinen Spermatogonien des Salamanders finden sich kleinere Karyosomen von verschiedener Gestalt mit länglich geformten gemischt vor. Oft sogar bilden die letzteren die ausschliesslichen Bestandteile des Kerns. Die länglichen Körperchen können, wenn sie einander sehr nahe kommen, zusammenfliessen, wodurch mehr oder weniger verzweigte Formen sich ergeben (Taf. XXVI, Fig. 5). Es ist noch zu untersuchen, ob nicht etwa die Osmiumfixierung beim Zustandekommen dieser Formationen eine Rolle spièlt. (S. auch Taf. XXVII, Fig. 1 b.)

Wie hieraus ersichtlich, sind die Karyosomen sowohl in bezug auf ihre Form, als auf ihre Zahl sehr verschieden. Es muss aber bemerkt werden, dass auch die kleinsten niemals so 
runde Formen zeigen, wie die ächten Nukleolen, welche in diesen Kernen aller Wahrscheinlichkeit nach fehlen.

In diesen Kernen befinden sich in der Regel keine streng runden, sowohl nach Einwirkung von Osmium, als auch von destilliertem Wasser gut sichtbaren Körper, das heisst wahre Nukleolen.

Durch ihr Verhalten erweisen sich sämtliche Körperchen dieser Kerne gleichartig. Auf Einwirken destillierten Wassers verschwinden alle im quellenden Kerne, und der Kern wird vollkommen homogen. Gegen Fixation und Färbungen verhalten sie sich alle gleich.

Die Karyosomen werden sowohl in den oberflächlichen, als auch in den tiefen Schichten bei der Flemmingschen Flüssigkeit und überhaupt bei allen guten Fixierern, vielleicht nur mit Ausnahme der eben erwähnten Erscheinung der Osmiumwirkung, in ihrer normalen Gestalt angetroffen. Bei der oberflächlichen Wirkung der Flemmingschen Flüssigkeit sieht man die Karyosomen wie im Leben, in homogener Umgebung, während sie in den tief fixierten Bildern von mehr oder weniger zahlreichen Körnchen umgeben sind (vergl. Taf. XXVI, Fig. 5, mit 6, 7).

Es gleicht auch bei diesen Kernen das Osmiumbild dem Lebenden, weil in beiden eine homogene Grundsubstanz mit freistehenden Körperchen zu sehen ist. Wir haben keinen Grund daran zu zweifeln, dass der homogene Charakter der Grundsubstanz auch hier, wie im früheren Falle bei den grossen Spermatogonien, den lebenden Verhältnissen entspricht.

Die durch die fällenden Behandlungen feinkörnig werdende Grundsubstanz entspricht der erythrophilen Substanz der Autoren, während die Karyosomen das "Chromatin" vertreten. Weder die Bilder vom frischen Material, noch die vom fixierten, berechtigen zur Annahme irgendwelcher anderen Bestandteile in diesen Kernen als einer Kernflüssigkeit und der Karyosomen.

Auch die Kerne der Spermatogonien, sowohl die der kleinen, als auch die der grossen liefern nach Osmium- und nach Kalibichromatfixation dichte volle Bilder, während sie bei anderen Fixationsmitteln, oder bei der Tiefen-Wirkung der Flemmingschen Flüssigkeit substanzärmer sind (Taf. XXVI, Fig. 6). Es wiederholt sich hier auch die Erscheinung, die ich auf die konservierende Wirkung der Osmiumsäure und des Kalibicbromats auf die fett- 
artigen Substanzen und auf die Auslösung derselben Substanzen nach den übrigen Fixationen zurückführe.

5. Über die Ruhekerne im allgemeinen.

Den Typus der nukleolären, karyosonffreien Kerne, wie wir ihn bei den grossen Spermatogonien gesehen haben, zeigen im allgemeinen die Kerne der Ei- und Ganglienzellen der Säugetiere, sowie auch zum Teile auch diejenigen der Epithelzellen. Den Typus der karyosombaltigen kleinen Spermatogonienkerne zeigen die meisten übrigen Kerne, die der Epithelzellen der Leber, der Niere, des Darmes etc. Besondere Beispiele liefern die Zellkerne einiger niederen Tiere: die schon oben erwahnten Kerne der Raupen, denen noch gewisse Kerne der Gastropoden und Arthropoden anzureihen sind. In diesen Kernen sind die Karyosomen kleiner und sind in grösserer Zahl vorhanden, so dass sie den Kern gleichmässig ausfüllen.

E. Korschelt ${ }^{1}$ ), der die Kerne der Spinndrüsen der Raupen untersuchte, spricht von Makro- und Mikrosomen, daneben aber spricht er auch von einem Gerüstwerke, obwohl von einem solchen nicht einmal in seinen eigenen Zeichnungen eine Spur zu sehen ist. Auch seine Abbildungen sprechen überall für isolierte Körperchen.

Ich kann auch Korschelt nicht beistimmen, wenn er in diesen kleinen Körperchen das hypothetische „Linin“ zu erkennen glaubt. Meves ${ }^{2}$ ) weist darauf hin, dass aus der Wirkung der Osmiumsäure, des destillierten Wassers, der Färbungen insgesamt auf diese Körperchen hervorgeht, dass sie die „Chromatin“Substanz darstellen, wozu ich bemerken will, dass die Körperchen meinen Karyosomen entsprechen.

Aus der Untersuchung dieser sehr kleinen, Karyosomen enthaltenden Kernarten wurde es mir besonders klar, dass die Bilder der lebenden Ruhekerne nicht so viel vor unseren Augen verbergen, wie man dies allgemein zu glauben pflegt, da ja diese ausnahmsweise sehr kleinen Karyosomen auch im Leben deutlich erkennbar sind.

1) E. Korschelt. Über die Struktur der Kerne in den Spinndrüsen der Raupen. Arch. f. milkr. Anat. Bd. 47. 1896.

3) Fr. Meves. Zur Struktur der Kerne in den Spinndrüsen der Raupen. Arch. f. mikr. Anat. Bd. 48. 1897. 
Eine eingehende Untersuchung der ruhenden Kerne ist sehr wünschenswert, weil es nach dem obigen noch nicht ausgeschlossen ist, dass in anderen Kernen von den erwähnten Typen abweichende Verhältnisse existieren. Für die Mehrzahl der Kerne dürfen wir aber annehmen, dass sie Flüssigkeitstropfen sind, die isolierte Körperchen, Nukleolen und Karyosomen enthalten. Auch zur Annahme einer Kernmembran ist bei den meisten Kernen kein Grund vorhanden.

Hiernach bestimmen drei Dinge das Wesen des ruhenden Kernes: die Kernflüssigkeit, die Nukleolen und die Karyosomen.

Die homogene Kernflüssigkeit kann als die chemische Werkstätte der Nukleolen und Karyosomen betrachtet werden. Die veränderliche Zahl, Grösse und Gestalt der Karyosomen weist in der Tat auf fortwăhrende Veränderungen hin. Die auffallendsten Verånderungen der Karyosomen aber treten mit Anfang der Mitose auf, wovon weiter unten berichtet wird.

Es ist unbedingt notwendig ${ }^{1}$ ), die zweierlei Körperchen, Nukleolen und Karyosomen scharf voneinander zu trennen. Durch Osmiumsăure, durch destiliertes Wasser, wie durch Färbungen können sie gut von einander unterschieden werden. Ich kann mich auch der Ansicht nicht anschliessen, dass die beiden Körperchen in genetischem Zusammenhange miteinander stehen.

Die Nukleolen erscheinen schon im ersten Augenblicke ihres Auftretens immer als scharfbegrenzte runde Pünktchen. Die Karyosomen dagegen treten nie, nicht einmal die kleinsten, in Gestalt so regelmässiger runder Punkte auf. Auch treten die mit der Mitose verbundenen Veränderungen in den zweierlei Körperchen nicht gleichzeitig auf, und auch hier zeigt sich ihr Verhalten grundverschieden. Zwar ist das Schicksal der beiderlei Körperchen im Beginne der Mitose, ihr Verschwinden an sich, dasselbe, doch ist die Art des Verschwindens in beiden grundverschieden. Die Karyosomen gehen - wie wir sehen werden - von auf-

1) Auerbach bezeichnet sämtliche Körperchen, welche in den Kernen vorkommen mit dem Namen Nukleolen. In A u erbachs Arbeit fällt aber gleich auf, dass in ihr von viel mehr Nukleolen die Rede ist, als in anderen Arbeiten; infolge der gemeinsamen Benennung Nukleolen werden die beiden Körperchenarten in seiner Arbeit nicht genügend unterschieden. (Organlog. Studien 1874, Breslan.) 
fallenden Erscheinungen begleitet zugrunde, die Nukleolen hingegen verschwinden kaum merkbar, indem sie sich fortwährend verkleinern.

Alles spricht dafür, dass die beiden Körperchen sowohl bezüglich ihrer Form und Substanz, als auch nach ibrer Entwicklung und ihrem Endschicksale grundverschieden sind.

Der Unterschied zwischen beiden ist ungefähr derselbe, wie der, welcher auch bisher zwischen den Netz-Strukturen und den Nukleolen angenommen wurde. Wie das Kerngerüst von den Nukleolen auch bisher scharf getrennt wurde, ebenso scharf sind auch die Karyosomen von den Nukleolen zu trennen. Schon hieraus ist zu ersehen, dass das "Chromatin" der Autoren durch die Karyosomen vertreten wird.

Es scheint, dass die Substanz der Nukleolen mit fettartigen Stoffen in nahem genetischen Zusammenhange steht. Ihre noch viel intensivere Färbung, als die des "Chromatins" spricht hierfür, da auch bei fettigen Degenerationen sehr intensiv färbbare Körnchen vorkommen, die mit der Entwicklung der fettartigen Substanzen im Zusammenhange stehen. Das Verhalten der Nukleolen gegenüber der Osmiumsâure, sowie ihre Unveranderlichkeit in destilliertem Wasser weisen auf dasselbe hin. Hierbei ist auch der Umstand beweiskräftig, dass bei der Weigertschen Markscheidenfärbung das Einzige, was sich neben den Myelinscheiden intensiv schwarz färbt, die Nukleolen der Nervenzellen sind, wăhrend alles übrige entfärbt ist.

Die fettartige Natur der Nukleolen wird dadurch noch wahrscheinlicher, dass Albrecht unabhăngig von diesen Erwägungen auf Grund von Beobachtungen über Myelin-Formationen annimmt, dass sich sowohl im Kerne, als auch in den Kernkörperchen fettartige Substanzen finden müssen.

Viele Kerne, wie die erwähnten Spermatogonien-Kerne, besitzen keine Nukleolen, sondern nur in destilliertem Wasser lösliche Karyosomen, woraus folgt, das solche Kerne nach Einwirkung destillierten Wassers vollkommen homogen werden.

Wenn man zu einem in destilliertem Wasser gequollenen und homogen gewordenen Kerne nachträglich Essigsäure zusetzt, dann wird die homogene Kugel zu einer feinkörnigen Niederschlagsmasse; die Karyosomen sind also in destilliertem Wasser zugrunde gegangen, sie sind aufgelöst worden. 
Ich erwähne diese Reaktionen, welche am besten an den kleinen Spermatogonien zu demonstrieren sind, auch deshalb, weil Flemming an einer Stelle auch in dem durch destilliertes Wasser homogen gewordenen Kerne ein gewisses Fortbestehen der Kernstrukturen behauptet und meint, dass diese noch nachher durch Essigsäure, wenn auch nicht ganz in ihrer ursprünglichen Form, wieder dargestellt werden könnten. Hiervon kann jedoch sicher keine Rede sein. Die von der Essigsäure erzeugten Fallungen stehen mit den ursprünglichen Formationen, mit den Karyosomen, in gar keinem Zusammenhange mehr.

Der erwähnte Versuch kann auch zur Erörterung des Begriffes "Chromatin" verwendet werden. Da durch destilliertes Wasser die Karyosomen vollständig aufgelöst werden, so werden sie eigentlich zur Kernflüssigkeit; wenn sich aber im Kerne ein wirklicher Nukleolus befand, so bleibt dieser unverändert. Auf diese Weise erhalten wir ein Kernbild, als ob wir es mit einer grösseren nukleolären Kernart zu tun hätten. Aber nicht nur dieses Bild, sondern auch das Bild der sekundären Essigsäure-Fällung ist in beiden Fällen gleich, da wir in den grossen nukleolären Kernen, sowie in den durch destilliertes Wasser homogen gewordenen, nach Einwirkung von Essigsäure oder anderer beliebiger eiweissfällender Mittel eine körnige Fällung der ganzen Kernmasse erhalten, welche der erythrophilen Substanz der Autoren entspricht. Das "Chromatin" kann also sowohl in den ausgewachsenen grossen Kernen, als auch in den mit destilliertem Wasser behandelten verschwinden.

Wie aber deshalb aus den mit destilliertem Wasser behandelten Kernen die „Chromatin"-Substanz sich nicht entfernt hat, ebenso kann nicht angenommen werden, dass in dem grossen nukleosomenresp. "chromatin" - freiem Kerne kein „Chomatin" vorhanden wäre.

Das Schicksal und die Entwicklung der Chromosomen ist berufen, diese Widersprüche năher zu beleuchten; dies soll der Gegenstand des folgenden Teiles dieser Arbeit sein.

\section{Mitose.}

Ursprung und Schicksal des Kernfadens.

1. Einleitung.

Von den im Innern des lebenden Kernes sich vollziehenden Vorgängen, als deren Resultat der Kernfaden erscheint, hat 
bisher noch niemand etwas gesehen, und man muss auch sogar die Möglichkeit einer unmittelbaren Beobachtung dieser Vorstadien der Mitose im Lebenden für ausgeschlossen halten.

So viel kann an lebenden Material festgestellt werden, dass der Kern grösser wird, die Karyosomen und Nukleolen verschwinden und das der ausgewachsene Kern etwas trüber wird, womit auch alle Beobachtungen erschöpft sind. Mit einem Male tritt aus dieser Trübung der Kernfaden hervor: das Resultat des Vorganges, doch nicht dessen Lösung.

Auch wenn die fixierten Bilder ganz sicher die treuen Kopien des Lebenden wären, bliebe in dergleichen Untersuchungen noch immer die oft schwierige Feststellung der richtigen Aufeinanderfolge der Bilder übrig. In den vorliegenden Untersuchungen verschwinden diese Schwierigkeiten neben den Schwierigkeiten der Beurteilung der fixierten Bilder.

In den Prophasen der Mitose, welche hauptsăchlich der Gegenstand dieser Untersuchungen sind, erreichen die Schwierigkeiten ihren Höhepunkt darin, dass ein und dieselbe Phase nicht nur durch die Wirkung verschiedener Fixierer abweichende Bilder gibt, sondern auch bei ein- und demselben Fixierungsmittel in mehreren voneinander gänzlich abweichenden Formationen erscheint. So schien es im Anfange fast unmöglich einen Weg zur Lösung zu finden, da ja auch die lebenden Verhältnisse in diesem Labyrinthe der Bilder keinen Pfad weisen.

Es stellte sich heraus, dass die in Rede stehenden Stadien des Kernlebens im Verhältnis sowohl zum ruhenden Kerne, als auch zu den späteren Phasen der Mitose, zur Entstehung von Kunstprodukten gleichsam prädestiniert sind. Der Kern ist in der Phase, wenn er seinen Charakter als ruhender Kern aufgibt, der mitotische Faden aber noch nicht erschienen ist, gegen Fixationsmittel ungemein empfindlich. Dies ist vielleicht aus dem Umstande verständlich, dass gerade ein Übergangsstadium besteht, in welchem die alte Ordnung schon zerstört, die neue jedoch noch nicht entstanden ist.

In nachfolgender Beschreibung werde ich die Reihenfolge einhalten, welcher ich bei meinen Untersuchungen selbst gefolgt bin und so will ich mit den gewöhnlichen Teilungen der Spermatogonien beginnen. Bei diesen sehen wir bekanntlich die einzelnen Stadien nicht durch so viele Exemplare vertreten, wie in den Reifungs- 
teilungen, dafür aber ist die Mannigfaltigkeit der verschiedenen Stadien umso grösser.

2. Prophasen der gewöhnlichen Mitosen der kleinen Spermatogonien in tiefen Schichten des fixierten objektes.

Sobald in den Spermatogonien-Nestern einige Zellen, gewöhnlich vier bis fünf nebeneinander, sich auf einmal gleichmässig: vergrössern, können wir schon bestimmt wissen, dass sie sich zur Mitose anschicken. Während des Wachsens nehmen sie gewöhnlich eine ovale Form an. Solche sich zur Mitose anschickenden Nester standen mir in gut fixiertem Zustande und intensiv schwarz gefărbt in grosser Menge und Mannigfaltigkeit zur Verfügung. Trotzdem konnten mir diese Zellen, wie es aus dem Folgenden ersichtlich wird, über die ersten Phasen der Mitose keine Orientierung geben, wofür auch der Umstand verantwortlich gemacht werden kann, dass ich nach dem allgemeinen Brauch zuerst nur die Bilder der tieferen Schichten des Präparates in Betracht gezogen habe.

Aus dem Torstehenden wissen wir schon, dass bei Kalibichr.Essigs.-Fixation die ruhenden Kerne der kleinen Spermatogonien mit körnigen Niederschlägen erfüllt sind, in welchen die isolierten Karyosomen in ihrer ursprünglichen Gestalt sichtbar bleiben.

Die Kerne unterscheiden sich schon in den allerersten Phasen ihres Teilungswachstums deutlich von ihren ruhenden Nachbaren dadurch, dass beide Bestandteile des Kernes, die Grundsubstanz und die Karyosomen, sich gleichzeitig verändern. Zuerst verlieren die Karyosomen ihren ursprünglichen Charakter, indem sie sich in grössere mit Fortsätzen versehene Flecken verwandeln (Taf. XXVI, Fig. 8a), dann treten auch in der früher gleichmässig körnigen Grundsubstanz Ungleichmässigkeiten, hellere Stellen auf. (Taf. XXVI, Fig. 10).

Der Untersucher ist diesen Stadien gegenüber in einer schwierigen Lage; denn so leicht es ist, diese Stadien an der Unregelmässigkeit der Formationen zu erkennen, ebenso grosse Schwierigkeiten bereitet die nähere Analyse derselben. Ich hatte die reinen, schwarzgefärbten tadellosen Bilder beliebig dünner Schnitte vor mir, ich beobachtete und kritisierte sie fortwährend 
und konnte mit ihnen doch nichts anfangen. Endlich zog etwas im Charakter der Grundsubstanz meine Aufmerksamkeit an sich. Die körnige Grundsubstanz des ruhenden Kernes, die eine Zeitlang auch noch im wachsenden und schon einige helle Stellen zeigenden Kerne noch den gleichen Bau zeigt, wandelt sich mit einem Male um, indem die Körner verschwinden und nur homogene Flecken, Streifen und Sterne sichtbar sind. (Taf. XXVI, Fig. 9, 12.)

Wir stehen hier vor einer wichtigen Veränderung. Die Unregelmässigkeit der Bilder ist als eine beständige Erscheinung zu konstatieren. An Stelle des scholligkörnigen Niederschlages des ruhenden Kernes erscheint auf einmal eine neue Formation. Diese Umwandlung der Grundsubstanz vollzieht sich zwar gesetzmässig, das Resultat der Veränderungen selbst zeigt jedoch kein regelmässiges Bild.

Das wichtigste in der Umwandlung ist, dass aus der körnigen Grundsubstanz des Ruhekernes eine Substanz von homogenem Charakter entstanden ist. Die aus dieser homogenen Substanz bestehenden Flecken und Streifen erscheinen aber in unendlich wechselnden Formationen, wodurch eine grosse Unregelmässigkeit der Bilder bedingt wird. Gleichzeitig greifen auch die hellen Flecken um sich, wobei sich auch der ganze Kern bedeutend vergrössert.

Diesen neuen, homogenen, oft streifenartigen Formationen musste ich erst, trotz ihrer Unregelmässigkeit, eine Bedeutung für die Mitose beilegen. In gewissen Stadien ist ja im Kerne gar keine andere Formation vorhanden, und so war es naheliegend, sie mit der Entwicklung des Kernfadens in Zusammenhang zu bringen.

Ich muss noch bemerken, dass bei der Fixation in Flemming scher Flüssigkeit die Verbältnisse ganz ähnlich sind. Die Bilder sind auch hier von demselben Charakter, sie entbehren in diesen Stadien auch hier jeder Regelmässigkeit; die Karyosomen und die Grundsubstanz verhalten sich auch ähnlich.

Übergangsbilder von diesen Formationen zum Kernfaden könnte man natürlich leicht finden, da der Nachweis von "Übergangsbildern" in cytologischen Untersuchungen zum Beweise eines schon aufgetauchten Gedankens überhaupt auf keine grossen Schwierigkeiten stösst. Die Präparate, die nicht nur "fixiert" sind, also nur einzelne Phasen erstarrt zeigen, sondern 
teilweise auch Kunstprodukte sind, können zur scheinbaren Stütze beliebiger Annahmen ein dankbares Material liefern. Auch die Phantasie des.Beobachters arbeitet unfreiwillig in dem engen Kreis der mikroskopischen Bilder, sie will die enge Welt dieser Bilder womöglich ausdehnen, die fixierten Bilder auf jede Weise beleben. In der Tat begegnete ich auch solchen Bildern, die für die Entwicklung des Kernfadens aus diesen Formationen hätten zeugen können.

Gewisse Winkelbrechungen dieser bizarren Formationen, von welchen ein sehr kleiner Teil in Taf. XXVI, Fig. 9 gezeichnet ist, erinnerten an jene Stadien, in welchen der schon gut erkennbare Faden auch rechtwinkelige Knickungen aufweist (Taf. XXVI, Fig. 13, 14), welche Stadien auch wirklich einander nahe stehen. So würde die Entwicklung des Kernfadens als das Zusammenfliessen dieser unregelmässigen, neu aufgetauchten Formationen erscheinen. Dies alles könnte leicht aus den fixierten Bildern gefolgert werden, wenn es nicht, auf einem ziemlichen Umwege, offenbar geworden wäre, dass diese eigentümliche neue Formation ein grobes Kunstprodukt ist.

Die Methoden der heutigen cytologischen Untersuchungen gebieten uns nicht nur mit unseren Folgerungen vorsichtig zu sein, sondern auch unsere Resultate, soweit es möglich ist, durch andere Untersuchungen zu kontrollieren. $\mathrm{Zu}$ dieser Kontrolle boten sich von selbst die Reduktionsmitosen dar. Die Teilungen stehen bei diesen in noch grösserer Zahl zur Verfügung, als bei den Spermatogonien, deren Mitosen zwar allerlei Stadien darboten, aber die einzelnen Stadien in relativ geringer Anzahl; in den Teilungen der "Spermatocyten" sind hingegen einzelne Stadien in grosser Zahl vertreten.

3. Prophasen der Reduktionsmitose, "Spermatocyten" der Autoren, nach Einwirkung der Flemmingschen Flüssigkeit.

Vor allem muss hervorgehoben werden, dass der Begriff "Spermatocyte" in seiner heutigen Verwendung, die sie als Zelle mit ruhendem Kern betrachtet, nicht zutrifft. Nach den gegenwärtigen Ansichten sollte der „Spermatocyt“ der der Reduktionsteilung zum Ausgange. dienende ruhende Kern sein. 
Die "Spermatocyten" des Salamanders mit deutlich sichtbaren Faden beschrieb zuerst Flemming als ruhende Kerne. In meiner vorausgeschickten "Kritik" wies ich darauf hin, dass diese Kerne schon zur Mitose gehören. Meves beschrieb ein anderes, etwas früheres Stadium der ,Spermatocyten ${ }^{*}$ mit sternartigen Formationen als ruhende Kerne. Diese sind aber ebenso keine ruhenden Kerne, wie die von Flemming beschriebenen; sie unterscheiden sich nur darin von einander, dass der von Me ves beschriebene Zustand ein früheres, dem ruhenden Kerne näherstehendes Stadium bedeutet. Diese Deutungen stammen daher, dass man zur Zeit die Entwicklung der "Spermatocyten" und den Verlauf der Reduktionsteilung als zeitlich getrennte Erscheinungen betrachtet. Die ,Spermatocyten-Entwicklung“ gehört aber schon durchaus zur Reduktionsmitose.

Das Wachsen der "Spermatocyten" ist nichts anderes, als die Wachstumsphase der Reduktionsteilung; gerade so, wie bei jedem sich zur Teilung anschickenden Kerne, besteht das erste Stadium auch hier im Wachsen des Kernes. Nun wird diese allgemeine mitotische Erscheinung nach den heutigen Beschreibungen als ein besonderer Vorgang, als "Spermatocyten"Entwicklung aufgefasst. Nach diesen Ansichten sollen die ruhenden Kerne der Spermatogonien anwachsen, um wieder in einen anderen Ruhezustand, in den der "Spermatocyten" überzugehen. Der Widerspruch liegt aber auf der Hand. Warum sollte der Kern den Ruhezustand verlassen, anwachsen, und dann wieder in den Ruhezustand übergehen? Die Entwicklung der ,Spermatocyten", d. h. das Wachsen der Spermatogonien ist eigentlich nichts anderes, als der Beginn der Reduktionsteilung. Die Eigentümlichkeiten dieser Teilung, die sowobl im früheren, als auch im späteren Stadium gleich auffallend sind, ändern an dem Wesen der Sache nichts.

In den Hodenkanälchen kommt sonach nur eine einzige Art von ruhenden Kernen vor, nümlich die Spermatogonien-Kerne, welche, wie bekannt, durch ihre zeitweilig auftretenden Teilungen die Zellenelemente in den Samenkanälchen vermehren; das sind die Teilungen, von welchen in den früheren Kapiteln die Rede war, und die ich gewöhnliche Teilungen der Spermatogonien nannte.

Die altesten Spermatogonien (im Hoden höherer Tiere die zum Lumen näher befindlichen), die im Salamander-Hoden von 
den grossen Spermatogonien am weitesten entfernt snd, schicken sich nicht vereinzelt, sondern in grösseren Gruppen zur Teilung an. Sie treten in einen modifizierten, länger als gewöhnlich danernden Teilungsverlauf ein, in welchem gerade das Auftauchen wichtiger Modifikationen, besonders die längere Dauer der einzelnen Stadien den Grund zu dem in Rede stehenden Missverständnis bildete. Wie die Wachstumsperiode der Reduktionsteilung bisher als isolierte Erscheinung, als ,SpermatocytenEntwicklung“" erschien, so führte das Längerdauern dieser ersten Teilungsphasen zur irrigen Annahme, als würden hier ruhende Kerne vorliegen.

Die Reifungsteilung nimmt also nicht mit den irrig gedeuteten „Spermatocyten"6 ibren Anfang, sondern mit den Spermatogonien, und die "Spermatocyten" der Autoren stellen schon ein Stadium der Mitose dar. Bei den Reifungsteilungen müssen wir also von denselben Ruhekernen ausgehen, wie bei den früheren gewöhnlichen Teilungen der Spermatogonien.

Statt von ,Spermatocyten" wäre es immer korrekter, von Prophasen der Reduktionsmitose zu sprechen, da jedoch jenes Wort augenscheinlich nicht eliminiert werden kann, werde auch ich es im folgenden weiter gebrauchen, doch sei betont, dass ich unter diesem Ausdrucke immer nur eine Phase der Reduktionsmitose verstehe.

Die Wirkung der Flemmingschen Flüssigkeit auf die ,Spermatocyten" des Salamander-Hodens bildete schon den Gegenstand einer Diskussion zwischen Flemming und Rawitz. Rawitz ${ }^{1}$ ) schreibt über diese Wirkung folgendes: ,Wahrend die Kerne der in zentralen Partien der Organe gelegenen Zellen das allgemein und mit Recht als normal betrachtete Aussehen haben (?) mit Recht: denn man sieht die betreffenden Strukturen auch in frischen Präparaten (?), zeichnen sich die Kerne der peripheren Partien durch die Abwesenheit der normalen Strukturen aus etc." Rawitz erklärt das Fehlen der Strukturen aus vermeintlichen „Chromatin"-Zertrümmerungen, wahhrend F l e m m in g den Grund der Unsichtbarkeit derselben in Lichtbrechungsverhältnissen sucht.

1) Dr. B. Rawitz: Über den Einfluss der Osmiumsäure anf die Erhaltung der Kernstrukturen. Anat. Anzeiger 1895, Bd. X., pag. 777. 
Aus dieser Diskussion wurde es aber klar, dass bisher kein Grund vorhanden war, entweder die eine oder die andere für die dem Lebenden entsprechende Formation zu halten. Die Aussagen von $R$ a w i t $z$ über die Sichtbarkeit der lebenden Strukturen können nur auf die ganz späten Stadien mit ausgebildetem Knăuel oder auf die Ruhekerne bezogen werden, da wir ja im Leben vor dem Erscheinen des Fadens nichts sehen, und die Wirkung der Fixierungsmittel noch nicht nach Verdienst gewürdigt wurde. Rawitz kennzeichnet übrigens seine Kontroverse mit Fle m ming objektiv und treffend, wenn er über die beiderseitige Argumentation sagt: "So steht also - wie gesagt - Deutung gegen Deutung."

In meiner Arbeit ${ }^{1}$ ) wies ich auf den Umstand hin, dass die oberflächliche Wirkung der Flemmingschen Flüssigkeit in solch auffallender Weise nur an diesen "Spermatocyten"-Kernen beobachtet werden kann. In den Abbildungen meiner erwähnten Arbeit ist sichtbar, dass die in der Peripherie nebeneinander liegenden ,Spermatocyten"- und Spermatogonien-Kerne auch bei ganz gleichen Fixations-Verhältnissen sehr verschieden aussehen. So wies ich schon damals darauf hin, dass dieses homogene Aussehen der "Spermatocyten"-Kerne ausser den von Flemming und Rawitz diesbezüglich erwahnten Faktoren in erster Reihe durch einen sehr wichtigen Faktor, durch den Zustand des Kernes beeinflusst werde.

Die Spermatocyten sind bekanntlich bei der oberflachlichen Wirkung meistens ganz homogen, sie zeigen keine Strukturen. Die Kerne der tiefer liegenden Zellen zeigen dagegen eine sehr auffallende sternförmige, intensiv färbbare Formation. (Vergl. in Taf. XXVII $d$ mit a.)

Von der Peripherie zum Zentrum der Hodenläppchen vorschreitend, sind auch anderweitige Bilder zu treffen; während in den zwei bis drei aussersten Zellenreihen die Kerne meistens fast ganz homogen sind, beginnen in den folgenden Reihen gewisse Formationen in ihnen allmählich sichtbar zu werden, in der siebenten bis achten Reihe werden diese immer deutlicher und besser färbbar, endlich treten im Zentrum die sternförmigen Formationen in ihrer ganzen Deutlichkeit zu Tage. (Taf. XXVII, Fig. 6, 8.)

1) Über die Fixierungs- (Härtungs-)Flüssigkeiten. Arch. f. mikr. Anat. 1898. Bd. 52. 
Unter diesen bunten Bildern finden sich neben solchen, die miteinander in Zusammenhang gebracht werden können auch solche, deren Charakter sehr verschieden ist. Die peripheren und zentralen Bilder sind so ungleich, dass man deren Zusammengehörigkeit, wenn man nicht ganz bestimmt wüsste, dass es sich um ein und dieselbe Kernart handelt, nicht einmal ahnen könnte. Von diesen verschiedenen Bildern wurden nach den heutigen Anschauungen, wie auch aus dem Rawitzschen Zitate ersichtlich ist, die zentralen Bilder für die den normalen Verbältnissen entsprechende gehalten. Es warf auch niemand die Frage auf, ob eigentlich von diesen vielerlei Bildern nicht etwa ein anderes Bild das richtige sein könnte. $\mathrm{Rawitz}$ und Flemming stritten auch nicht darüber, ob die zentralen oder peripheren Bilder die richtigen seien - beide halten unstreitig die zentralen Bilder für die naturgetreuen - sondern weichen nur in den Erklărungsversuchen der peripheren homogenen Bilder voneinander $a b$.

Den ersten Impuls zur richtigen Deutung dieser Verhaltnisse gab das Aufsuchen solcher Schnitte, in welchen die ,Spermatocyten" und Spermatogonien unmittelbar nebeneinander an der Peripherie liegen, wo also die beiden Arten von Zellen notwendigerweise in absolut gleicher Weise der Einwirkung des Fixierers ausgesetzt waren. Da war das Ergebnis doch ein ganz verschiedenes (Taf. XXVII, Fig. 1).

In diesen Präpäraten, wo die beiderlei Kerne der Einwirkung der Flüssigkeit augenscheinlich vollkommen gleichartig ausgesetzt waren, verschwindet nur in den "Spermatocyten" das "Chromatin", in den unmittelbar benachbarten Spermatogonien aber bleibt nicht nur das "Chromatin" erhalten, sondern es entspricht das Bild auch vollkommen dem Lebenden und ist auch die Färbbarkeit der Karyosomen, wie aus den Abbildungen ersichtlich ist, tadellos; in den an der Peripherie liegenden "Spermatocyten" aber sehen wir ausser einigen sehr kleinen Nukleolen in der Regel nichts, weder im gefärbten, noch im ungefärbten Präparat (Taf. XXVII, Fig. 1 d).

Da bei der oberfächlichen (peripherischen) Wirkung das Aussehen der Spermatogonien ganz den Bildern lebender Kerne entspricht, so müssen wir auch an die Möglichkeit denken, dass auch die „Spermatocyten" bei gleicher Einwirkung dem Lebendigen Archiv f. mikrosk. Anst. Bd, 66 . 
ăhnlichere Bilder liefern. Man muss mit dieser Möglichkeit umsomehr-rechnen, als wie gesagt, bisher gar kein Grund vorhanden war, irgend eines von den vielen Bildern, welche diese Zellen bei Wirkung der Flemmingschen Flüssigkeit zeigen, bezüglich der Lebenstreue zu bevorzugen. Da ich aber den Vorteil der peripherischen Wirkung bezüglich der Spermatogonien beweisen konnte, so bleibt es kaum verstandlich, warum sie gerade für die Spermatocyten unvorteilhaft wăre, wie es die Autoren bisher meinten, die zur Erklärung der Erscheinung hypothetische „Zertrümmerungen", „Lichtbrechungsverhaltnisse “, „Überfixationen " etc. annabmen. Eine nähere Klărung dieser Frage können wir nur von der Berücksichtigung der Wirkung der Fixierungsmittel erwarten.

Wenn wir nun die Wirkung der Fixierungsmittel erwägen, so gelangen wir logisch zu dem Resultat, dass gerade die peripherische (oberflächliche) Wirkung diejenige ist, welche in erster Reihe unser Vertrauen verdient; bei dieser Einwirkung kommt jener Faktor zur Geltung, den man seit jeher zu erwahhnen gewohnt war, dass nămlich die Fixierungsmittel müssen momentan auf die lebenden Zellen wirken; doch war dieses Moment bisher nicht berücksichtigt worden, wie die Diffusionsverhaltnisse überhaupt nicht in Betracht gezogen wurden.

Man muss aber stets den wichtigen Umstand vor Augen halten, dass auch bei den für die schnellsten Fixierungsmittel gehaltenen Flüssigkeiten im Innern des Objektes die Wirkung auf dem Wege der Diffussion nur sehr langsam und allmăhlich zur Geltung kommt. Bei chemischen Fixationen kann von einer momentanen Wirkung im Innern des Objektes keine Rede sein; die fixierenden Bestandteile kommen ja erst nach mehreren Stunden, ja selbst nach Tagen, zur Geltung und zwar gelangen sie erst sehr verdünnt ins Innere der Objekte, und es können Tage und Wochen vergehen bis zur vollständigen Durchtrănkung.

Die notwendige Folge der langsamen Diffusion ist, dass im Zentrum die Zellen lange Zeit ohne Einwirkung bleiben, so, dass sie auch im besten Falle hier gewissen Veränderungen unterliegen müssen, bevor die Fixierungsbestandteile auf sie einwirken können. Bemerkenswert ist auch der Umstand, dass auf dem Wege der Diffusion die einzelnen Bestandteile der Flüssig- 
keiten zuerst núr in grosser Verdünnung einwirken, sodass die Zellen zunächst mit verdünnten Fixierungsmitteln in Berührung kommen. Dieses Stadium der Fixation ist eben für das gefăhrlichste zu halten.

Auch bei den kleinsten Stückchen, z. B. von 1-2 mm Durchmesser, müssen wir diese Verhältnisse in Betracht ziehen und auch bei diesen in den zentralen Teilen Veränderungen annehmen, die bereits eintreten, bevor die Fixierungsflüssigkeit, langsam diffundierend, zu ihnen vordringt.

Die in den zentralen Partien gelegenen Kerne erscheinen, abgesehen von den erwähnten bizarren ästigen Figuren bell, als wären sie ohne Grundsubstanz (s. Taf. XXVII, Fig. 4, 6, 8), während die Kerne der an der Peripherie liegenden Zellen eine, den ganzen Kern ausfüllende Grundsubstanz aufweisen (s. Taf. XXVII, Fig. 5, 7).

Alle Tatsachen berücksichtigend, komme ich notwendigerweise zu dem Resultate, dass die bizarren Formationen der zentralen Kerne nichts anderes, als Kunstprodukte sind, und dass eben die peripherischen Bilder diejenigen sind, die der Wahrheit mehr entsprechen. Die peripheren Kerne zeigen auch keine besonderen Konturen, geradeso wie die frisch untersuchten. Sie erscheinen auch so, wie die lebenden Kerne, gleichmässig ausgefüllt.

Was entspricht nun in Wirklichkeit diesen sternförmigen Kunstprodukten? Diese Frage wird nicht so leicht zu beantworten sein, da wir noch etliche Kernbilder haben, zwischen denen wir wählen müssen. Selbst bej der peripherischen Wirkung der Flemmingschen Flüssigkeit sind mehrere verschiedenartige Bilder vorhanden, weiter unten wird dann noch von der Kaliessigsäure-Fixation berichtet, bei welcher dieselben Kerne wieder ganz anders gestaltet erscheinen. Nahere Anhaltspunkte werden wir aus der Vergleichung beider Bilderarten gewinnen.

Was die Flemmingsche Flüssigkeit anbelangt, so ist zuerst daran festzuhalten, dass die mehr homogenen peripheren Bilder dem natürlichen Zustande am nächsten kommen, und dass diese Homogenität keine spezifische Osmiumwirkung ist. Ich bemerke auch schon hier, dass dieser homogene Zustand des Kernes im folgenden als Charakter der sich zur Mitose anschickenden Kerne sich entpuppen wird, da im Anfange der Mitose jede 
vorher bestehende Formation in erster Reihe in diffuse Verteilung übergeht, wie alsbald erwiesen werden soll.

\section{Zerfall der Karyosomen.}

Wenn meine Behauptung, dass diese diffuse Verteilung der Substanz der Spermatocytenkerne eine allgemeine Erscheinung der Mitose darstellt, richtig ist, so muss man auch bei anderen Teilungen ähnlichen Erscheinungen begegnen. Hier bieten sich nun die gewöhnlichen Teilungen der Spermatogonien, von welchen schon oben die Rede war, als ein vorteilhaftes Untersuchungsobjekt dar.

Die Beschreibung der Teilungen der Spermatogonien geschah vorhin auf Grund der bei der zentralen Einwirkung erhaltenen Bilder. Diese sind auch von den übrigen Forschern wegen der an ihnen hervortretenden auffallenden Strukturen vorzugsweise in Betracht gezogen worden. Auch sind in der peripherischen Einwirkungszone die Teilungsbilder seltener anzutreffen. Ich wandte meine Aufmerksamkeit besonders diesen Bildern zu, die nach dem oben Erörterten den natürlichen Zuständen mehr entsprechen müssen.

Es stellte sich nun heraus, dass auch bei den gewöhnlichen Teilungen der Spermatogonien zuerst die geformten Bestandteile des Kerns alle verschwinden und dadurch eine homogene Beschaffenheit desselben entsteht. Diese Erscheinung, die an lebenden Kernen nur im allgemeinen konstatiert werden kann, lässt sich in den fixierten Bildern der Spermatogonien von Schritt zu Schritt verfolgen.

So fand ich ganz eigentümliche Bilder in der peripherischen Wirkungszone der Flüssigkeiten, welche nur als Zerfall der Karyosomen gedeutet werden können (Taf. XXVI, Fig. \&a und 11). Aus diesen Bildern ist es ersichtlich, dass in dem wachsenden Kerne die Karyosomen sich erst fleckig ausbreiten, auch erscheinen an ihren Oberflachen Fortsätze und entstehen in ihrem Innern Vakuolen; alle diese Erscheinungen leiten den Schwund der Karyosomen ein. Sämtliche Karyosomen eines Kernes zeigen gleichzeitig diese Erscheinungen, wodurch der Kern immer bomogener wird und endlich entsteht auch hier ein ähnlicher Zustand, wie er bei den „Spermatocyten" schon längst die Aufmerksamkeit auf sich lenkte. 
Wir werden später zeigen können, dass zwischen den zwei Teilungsarten, der gewöhnlichen und der Reduktions-Teilung, wichtige Unterschiede bestehen. Ein solcher Unterschied besteht schon in diesen frühen Stadien darin, dass bei den gewöhnlichen Teilungen sofort nach der diffusen Verteilung der Karyosomen, ja sogar schon wăhrend des Zerfalls derselben, eine neue Formation, die erste Spur des Fadens erscheint (Taf. XXVI, Fig. 3 a), was auch mit dem schnellen Verlaufe der gewöhnlichen Mitose übereinstimmt. Bei der Reduktionsteilung dagegen dauert diese diffuse Verteilung entsprechend der längeren Dauer des ganzen Prozesses auch länger.

Um dieselbe Erscheinung, d. i. das Verschwinden der Karyosomen, auch im ersten Stadium der "Spermatocyten" der Autoren zu sehen, muss man sich eines Hodens bedienen, in welchem eben die massenhafte Reduktionsteilung beginnt, oder was dasselbe bedeutet, die "Spermatocyten-Entwicklung " ihren allerersten Anfang nimmt. Einen solchen in der Entwicklung begriffenen Spermatocyten zeigt Taf. XXVII, Fig. 2 a und 10.

Allein wenn ich auch nicht in der Lage wäre, in meinen Abbildungen einen solchen Übergangskern zeigen zu können, so müsste das Bestehen eines solchen Übergangszustandes schon als notwendige Folgerung angenommen werden, da ja jeder homogene "Spermatocytenkern" durch die Umwandlung eines Spermatogonienkernes entsteht, was ja ohne das Verschwinden der Karyosomen nicht verständlich wäre.

Gehen wir nun aber in unseren Folgerungen einen Schritt weiter. Ich fand, dass der homogene Charakter der Kerne in der peripherischen Wirkungszone in erster Reihe eine Teilungserscheinung ist. Ich habe die Anfangsstadien beider Teilungsarten in der peripherischen Wirkungszone verglichen und das Verschwinden der Karyosomen in beiden Fällen übereinstimmend gefunden.

Nach diesen Erfahrungen an der peripherischen Zone kehren wir nun wieder zu den Bildern der zentralen Wirkungszone zurück. Wie sind nunmehr diese Bilder zu deuten?

$\mathrm{Da}$ in der peripherischen Wirkungszone bei diesen beiden Teilungen eine gewisse Übereinstimmung vorhanden war, so muss man erwarten, auch in der zentralen Zone eine ähnliche Übereinstimmung $\mathrm{zu}$ finden. So gelangte ich zu dem Resultate, 
dass die unregelmässigen Formationen der Spermatogonien nichts anderes sind, als eine den sternigen Formationen der "Spermatocyten" entsprechende Erscheinung. (Vergl. Taf. XXVI, 12 mit Taf. XXVII, 6, 8.)

Sind diese eigenartigen Formationen auch Kunstprodukte, so sind sie dennoch für die allerersten Anfangsstadien der Mitose charakteristisch. So wurde mir die Bedeutung der sehr eigentümlichen Kernbilder der grossen Spermatogonien klar, wie sie in Taf. XXV, Fig. 6 u. 7 gezeichnet sind, über welche ich mir lange keine Vorstellung machen konnte. Sie stellen alle das erste Anfangsstadium der Mitose vor; doch sind sie nur als Kunstprodukte $\mathrm{zu}$ betrachten.

\section{Ursprung des Fadens bei den gewöhnlichen Mitosen der Spermatogonien.}

Die soeben beschriebenen Verhăltnisse berühren bereits die schwierigsten Fragen unseres Gegenstandes, den Ursprung des Kernfadens. Ich werde aber auch in dieser Frage zuerst die gewöhnlichen Teilungen der Spermatogonien betrachten, und nachher die Reduktionsteilung.

Bei den Teilungen der grösseren Spermatogonien kann in der peripherischen Wirkungszone der Flemmingschen Flüssigkeit die Entstehung des Fadens bis in die frühesten Stadien verfolgt werden. Besonders an den mittelgrossen Spermatogonien konnte ich beobachten, dass gleich nach dem Zerfall der Karyosomen in der homogenen Grundsubstanz des Kernes kleine, an der Grenze der Sichtbarkeit stehende Pünktchen anftreten, welche schon sehr früh nicht als selbständige isolierte Körperchen, sondern als Teile gewisser mutmasslicher Formationen erscheinen (Taf. XXVI, Fig. 3 a u. b, Taf. XXV, Fig. 8 a).

$\mathrm{Zu}$ dieser Zeit kann der angewachsene Kern noch ein mannigfaltiges Bild zeigen, da die letzten Spuren der Karyosomen, eventuell der Nukleolen und auch die oben erwähnte feine neue Formation gleichzeitig in ihm vorhanden sein können, wie es in Taf. XXVI, Fig. 3a sichtbar ist. Bald stellt sich jedoch heraus, dass von diesen drei Bildungen nur die letztgenannte eine $\mathrm{Zu-}$ kunft hat, indem sehr bald jene wichtigen Bilder entstehen, in welchen alles verschwunden ist, bis auf die neuen feinen Formationen ('Taf. XXVI, Fig. 3 b, Taf. XXV, Fig. 8 b). 
In diesen Stadien stellt sich auch klar heraus, dass die zuerst aufgetauchten kleinen Pünktchen eigentlich den Winkelbrechungen sehr feiner Fadenbildungen entsprechen. Diese Winkelbrechungen sind auch später noch sichtbar, wenn der Faden schon mehr entwickelt und bedeutend dicker geworden ist (Taf. XXV, Fig. 9, Taf. XXVI, Fig. 16). Das punktartige Aussehen derselben ist so charakteristisch (siehe besonders Taf. XXV, Fig. 8 a, b), dass wir mit Hülfe derselben die Erscheinung bis zur Grenze der Sichtbarkeit verfolgen können, denn diese Winkelbrechungen sind es, die zuerst als kleine Pünktchen auftauchen und wahrnehmbar werden.

Diese Verhältnisse können besonders an den grossen und mittelgrossen Spermatogonien studiert werden. An diesen kann ohne jeden Zweifel festgestellt werden, dass der Faden in der Tat aus unendlich feinen Bildungen seinen Ursprung nimmt. Dass diese feinen Anfangsformationen tatsächlich der Entwicklung des Fadens entsprechen, braucht an diesen Objekten nicht näher bewiesen zu werden, denn von diesen feinen Formationen führt der Weg direkt zu dem in der ganzen Ausdehnung des Kernes auftretenden feinen und deutlich sichtbaren Faden. Sobald wir die feinsten Formationen wahrnehmen, d. h. die erwähnten Pünktchen sehen, merken wir auch sofort im Charakter derselben den unmittelbaren Zusammenhang mit dem feinen Anfangsfaden.

Eine besondere Bedeutung in diesen Erscheinungen hat der Umstand, dass der Faden als vollkommen neues, selbständiges Gebilde aus der Konzentration einer diffus verteilten Masse entsteht und als ein neu entstehendes Gebilde zuerst nur in ausserordentlicher Feinheit erscheint, um erst stufenweise stärker zu werden. Das bisher bekannte ständige Dicker- und Stärkerwerden des Fadens ist nur eine Fortsetzung, die letzte Phase dieser von Anfang an allmählich fortschreitenden Erscheinung.

Besonders bemerkenswert ist ferner bei diesen gewöhnlichen Teilungen, dass der feine Kernfaden vom ernsten Momente seiner Entstehung mit glatter Oberfläche und Konturlinie versehen, wie mit einfachen feinen, reinen Federstrichen gezeichnet erscheint. Es ist ausserdem noch von Wichtigkeit, dass die Entwicklung des Fadens innerhalb des ganzen Kerns auf einmal beginnt, und dass der Faden vom Anfang an als zusammenhängendes Ganzes zu betrachten ist ('Taf. XXV, Fig. 8 b und Fig. 9). 
Es ist sehr auffallend, dass die Anfangsstadien des Fadens nur in der peripherischen Wirkungszone zu beobachten sind. welcher Umstand damit zu erklären ist, dass diese Anfangsstadien der Mitose in der zentralen Wirkungszone zugrunde gehen.

Zum Studium des Ursprunges des Kernfadens sind die kleinen Spermatogonien nicht vorteilhaft. Von der Entstehung des Kernfadens erhielt ich bei ihnen keine so überzeugenden Bilder, wie bei den grossen Spermatogonien; man darf aber annehmen, dass die Verhălnisse auch bei ihnen wesentlich die gleichen sind. Auch hier zeigen die Bilder aus der peripherischen Zone am klarsten den Faden, jedoch ist es mir nicht gelungen, die unendlich feinen Formationen, wie in den obigen Zellen aufzufinden. Die Kerne der kleinen Spermatogonien sind reich an Karyosomen, die Auflösungserscheinungen der vielen Karyosomen aber verdecken so sehr die ersten Spuren des Fadens, dass wir hierin vielleicht auch den Grund für die Schwierigkeiten der Beobachtung finden können. Hieraus erklärt sich, dass wir bei diesen Kernen den Eindruck gewinnen, als ob nach der Lösung der Karyosomen sofort ein dicker Faden erschiene. Hierzu kommt noch, dass die Kerne viel kleiner sind, als die obigen, und schon deshalb zur Untersuchung weniger geeignet sind. Wir gehen daher zu den Reduktionsmitosen über, bei welchen die Untersuchungen der fraglichen Erscheinungen weitaus lehrreicher sind.

6. Ursprung des Fadens bei der Reduktionsmitose.

Durch die Wirkung der Kalibichromat-Essigsäure werden die Verhältnisse für den ersten Anblick komplizierter. Die Zahl der mannigfaltigen Bilder der "Spermatocyten " wird noch grösser und es erscheinen wieder neuere, von den früher beschriebenen abweichende Formationen. Auch bei dieser Flüssigkeit besteht zwischen der peripherischen und zentralen Wirkungszone ein grosser Unterschied (vergl. Taf. XXVIII, Fig. 5 a mit 5 b). Auch hier erscheinen die an der Peripherie momentan fixierten Kerne anders beschaffen, als die zentral gelegenen langsam fixierten. Die Formationen der zentralen Kerne sind so beschaffen, wie die der zentralen Kerne bei der Flemmingschen Flüssigkeit, d. h. sie bestehen in beiden Fällen aus sternförmigen, bizarren, deutlich sichtbaren und färbbaren Bildungen (vergl. Taf. XXVIII, Fig. 4 
mit Taf. XXVII, Fig. 6, 8). Der Umstand, dass in beiden Fällen die zentralen Bilder übereinstimmen, liefert aber für ihre Lebenstreue, wie wir noch naher seben werden, durchaus gar keinen Beweis.

Obwohl die peripherischen Kerne der "Spermatocyten" bei den beiden Flüssigkeiten auf den ersten Blick sehr verschieden erscheinen, besitzen sie trotzdem einen wichtigen gemeinsamen Zug, der darin besteht, dass sie in beiden Fällen in ihrer ganzen Ausdehnung dichter ausgefüllt sich darstellen, und dass die Substanz des Kernes sich in feinerer Verteilung befindet, als in den zentral gelegenen Kernen.

Die Wirkung der Kaliessigsăure kann leichter erklärt werden, und sie ist deshalb zur Beleuchtung der Verhältnisse vorteilhafter, als die Flemmingsche Flüssigkeit; wir haben bei ihr mit der komplizierten Wirkung der Osmiumsäure nicht zu rechnen; es sind nur Essigsäure und Kaliumbichromat vorhanden, welche beide zusammen in der peripherischen Zone eine momentane Gerinnung hervorrufen.

Die Kaliessigsaure - Bilder der "Spermatocyten“ an der Peripherie können unsere Aufmerksamkeit in vollem Maße in Anspruch nehmen. Bei mittleren Vergrösserungen erscheint der Kern meistens diffus körnig; mit Immersions-Linse und ausgezogenem Tubus bei günstiger Beleuchtung kann man sich aber überzeugen, dass er einen sehr feinen fädigen Charakter besitzt (Taf. XXVIII, Fig. 1, 2). Die Bilder zeigen je nach den Stadien etwaige Mannigfaltigkeit; gleichzeitig mit dieser feinen Verteilung in Fadenform können in den Kernen noch grössere Flecke: letzte Spuren der Karyosomen aufgefunden werden. Später erhält auch die feine Verteilung einen gleichmässigeren Charakter. Ausser den in den Abbildungen dargestellten ungemein feinen Formationen können noch feinere, sowie auch etwas gröbere wahrgenommen werden.

Charakteristisch ist noch für diese Kerne, dass in ihnen eine meist exzentrisch gelegene ziemlich grosse Vakuole anzutreffen ist, welche von den feinen Formationen umgeben wird (Taf. XXVIII, Fig. 1, 2, 3).

Diese eigentümliche Art der diffusen Verteilung der Kernsubstanz muss schon als zum Charakter der Reduktionsteilung gehörig betrachtet werden, denn ich konnte sie bei den gewöhn- 
lichen Teilungen der Spermatogonien nicht beobachten, so dass also der Unterschied zwischen den zwei Mitosen schon gleich mit der Auflösung der Karyosomen auftritt.

Eine wichtige Frage wäre nun noch, ob wir diese feinen Formationen, die auch bei den stärksten Vergrösserungen als aus ausserordentlich feinen fädchenartigen, bazillenähnlichen Körperchen bestehend erscheinen, für lebende Formationen halten sollen? Die Formation ist ganz eigenartig; sie stellt nicht die einfachen granulierten Fällungsfiguren dar, wie es z. B. bei dem ruhenden Kerne der Fall war. Wenn man nun noch in Betracht zieht, dass diese Bilder eben in der peripherischen Wirkungszone erscheinen, so muss man nach den obigen Auseinandersetzungen ihnen eine gewisse Realităt zuerkennen, und dies erscheint umsomehr berechtigt, da dadurch auch die peripherischen Bilder der Flemmingschen Flüssigkeit ihre Erklärung finden können.

Die der Flemmingschen Flüssigkeit ausgesetzten peripherischen Kerne sind zwar in den ersten zwei Reihen fast vollkommen homogen, höchstens mit einigen kleinen Nukleolen versehen, in der dritten bis vierten Reihe aber, die noch in den Kreis der peripherischen Wirkung fallen, sind schon gewisse Formationen sichtbar (Taf. XXVII, Fig. 1, 5, 7 u. 11). Der Charakter dieser Formationen besteht nun darin, dass sie auch ausserordentlich fein sind und nur gegen das Zentrum hin gröber werden, bis sie endlich in die groben sternförmigen Bilder übergehen ('Taf. XXVII, Fig. 6, 8).

Bisher haben wir nur die der zentralen Wirkung ausgesetzten Kerne davon ausgeschlossen, dass sie den Verhältnissen im Leben entsprechen; von den vielerlei Bildern der peripherischen Wirkung der Flemmingschen Flüssigkeit können wir aber noch immer wählen, welche von ihnen eigentlich für naturgetreu gehalten werden sollen. Die in den peripherischen KaliessigsäureBildern wahrnehmbaren sehr feinen Formationen können jetzt mit den bei der peripherischen Wirkung der Flemmingschen Flïssigkeit sichtbaren feinen Formationen in einen gewissen Zusammenhang gebracht werden. Besonders jene Bildungen, welche in der dritten bis vierten Zellenreibe $\mathrm{zu}$ beobachten sind. Hier erscheinen in der homogenen Grundsubstanz kleine Pünktchen, von welchen wir aber doch konstatieren können, dass sie keine 
selbständigen Körperchen, sondern nur Teile anderer feiner Formationen sind (Taf. XXVII, Fig. 1 c, 5 a).

Es sind auch Kerne zu finden, in welchen feine netzartige Formationen zu vermuten sind (Taf. XXVII, Fig. 11). Das Wesen der feinen Formationen bei der Wirkung der Flemmingschen Flüssigkeit bleibt aber immer zweifelhaft, denn sie sind, solange sie in der aussersten peripherischen Wirkungszone erscheinen, kaum sichtbar, sobald sie aber weiter nach innen liegen, geht mit der besseren Sichtbarkeit und Farbbarkeit der Formationen die Erscheinung des Zusammenfliessens Hand in Hand.

Bei der Beurteilung der Wirkung der Flemmingschen Flüssigkeit verfahren wir nach allem am richtigsten, wenn wir den Mittelweg wahlen, und weder die zentralen, noch die aussersten peripherischen Bilder bevorzugen.

Bezüglich der Zellen der äussersten Reihen müssen wir auch aus anderen Gründen auf der Hut sein. Der Osmium wirkung entsprechend, muss in der peripherischen Wirkung gerade in diesem heiklen Stadium auch die Möglichkeit des Verschwindens gewisser feiner Strukturen noch immer angenommen werden, wenn auch nicht in dem Maße, wie man bisher hierfür die Osmiumsăure verantwortlich machte. Wir werden am wenigsten irren. wenn wir die Wirklichkeit nicht in den total homogenen ersten Reiben, sondern in den gleich auf diesen tolgenden feinen Formationen suchen, da diese mit den peripherischen KaliessigsăureBildern doch in einen gewissen Einklang gebracht werden können.

Es sei nochmals betont, dass wir uns am wenigsten davon irreleiten lassen dürfen, dass die zentralen Bilder bei den zwei Flüssigkeiten übereinstimmen, da bei beiden die zentrale Wirkung auf ganz dieselben Faktoren zurückgeführt werden muss.

In der zentralen Wirkungszone beider Flüssigkeiten stagnieren die Kerne in gleicher Weise. In beiden Fällen tritt zuerst die schneller einwirkende Essigsäure in Aktion, nachher folgt auf dem Wege noch langsamerer Diffusion in einem Falle die Chromsãure, im anderen Falle das Kalibichromicum. Diese beiden können aber in dem stagnierten Kerne, nachdem die Essigsäure die Fällung und die Fixation des Kernes schon allein bewirkt hat, keine wesentlichen Veränderungen mehr hervorrufen. Die Osmiumsäure kommt im Zentrum entweder gar nicht, oder 
nur verspätet zur Geltung und kann sie hier noch weniger, als die Chromsäure Veränderungen hervorrufen.

Auch bei Gebrauch irgendwelcher anderer făllender, sogar auch essigsäurefreier Fixationsmittel, wird das zentrale Bild dieser Kerne eigentlich im grossen und ganzen immer dasselbe bleiben, da das Wesentliche bei den zentralen Bildern auf der Stagnation und verspäteten, langsamen Gerinnung beruht, was infolge der Langsamkeit der Diffusion bei allen chemischen Mitteln zutrifft. Ich betone dies deshalb, damit nicht jemand für die Lebenstreue der in Rede stehenden Formationen die verschiedensten FixationsFlüssigkeiten als ebensoviele separate Beweise vorbringe.

Wenn es auch gewiss ist, dass die wahren Formationen in den ersten Phasen der Reduktionsmitose bei beiden Flüssigkeiten in den peripherischen Bildern $\mathrm{zu}$ suchen sind, so kann und will ich hier über das eigentliche Wesen dieser Formationen nicht entscheiden. Im Rahmen dieser Arbeit soll es genügen, darauf hinzuweisen, dass auch in den Reduktionsmitosen die anwachsenden Kerne zuerst homogenisiert werden, und dass die Fadenbildungen auch hier neu entstehen.

\section{Erklärungsversuch der "Synapsis.“}

Eine auffallende Eigentümlichkeit der Reduktionsteilung, das Yerbalten des dicken Kernfadens und der Chromosomen, wurde zuerst von Flemming durch die Aufstellung seiner heterotypischen Teilung gewürdigt zu einer Zeit, in welcher noch von einer Reduktionsteilung nicht die Rede war. Die zweite bekannteste Eigentümlichkeit dieser Teilungen ist das von Moore "Synapsis" genannte Stadium.

Diese zwei Erscheinungen: das Synapsis-Stadium und das zuerst von Flemming beschriebene Verhalten der Chromosomen sind nur die auffallendsten Abweichungen der Reduktionsteilungen von den gewöhnlichen. Wir können aber im ganzen Verlaufe der Reduktionsteilung vom Anfange bis zum Ende kontinuierliche Abweichungen in allen Phasen konstatieren, jedoch in der Weise, dass das Schema, die wesentlichen Phasen der Mitose ebenso vorhanden sind, wie in den gewöhnlichen Teilungen.

Eine gemeinsame Erscheinung in den zweierlei Teilungen ist der Zerfall, das Verschwinden der Karyosomen. Wir haben 
keinen Grund einen grossen Unterschied zwischen diesen Zerfallserscheinungen der Karyosomen bei den zwei Arten von Teilungen anzunehmen, trotzdem sind die Bilder schon in diesen frühesten Wachstumstadien nicht vollständig gleich. Bei der Reduktionsteilung ist das Wachstum ausgiebiger und der wachsende Kern ist meist von regelmässig kugeliger Gestalt, während für die gewöhnliche Teilung der Spermatogonien charakteristisch ist, dass sie während des Wachstums ovale Form annehmen und nicht so gross werden. Ein tiefgreifender Unterschied besteht auch darin, dass bei den Reduktionsteilungen die Veränderungen viel langsamer vor sich gehen. Bei den gewöhnlichen Teilungen gehen die Veränderungen so schnell vor sich, dass, wie wir oben gesehen haben, nach der Auflösung der Karyosomen die ersten Spuren des neuen Fadens sofort erscheinen; bei den Reduktionsteilungen dagegen dauern nach dem Verschwinden der Karyosomen das Stadium der diffusen Verteilung, so wie auch die späteren Stadien länger.

Am auffallendsten ist aber jener Unterschied zwischen den zwei Teilungen, dass in Synapsis-Stadium die vorher gleichmässig, diffus verteilte Kernsubstanz in eine gewisse einseitige Anhăufung übergeht. Diese färbt sich intensiv, so dass sie in den Präparaten die Aufmerksamkeit besonders auf sich lenkt.

Es sei bemerkt, dass eine ähnliche einseitige Anhäufung auch als gewöhnliches Fixationsprodukt vorkommt, das sowohl an tierischen, wie auch an Pflanzenkernen auftreten kann, und darin besteht, dass in der Richtung des Einwirkens von starkem Alkohol die Substanz des Kernes sich auf der einen Seite zusammenzieht.')

Die Lage der einseitigen Anhäufung im Kerne der Spermatocyten steht aber mit der Diffusionsrichtung der Fixierungsflüssigkeit in keinem Zusammenhange und ist bei den meisten Fixationsverfahren vorhanden, abgesehen von der peripherischen Osmiumwirkung, wie sie z. B. bei der Anwendung der Flemmingschen Flüssigkeit vorhanden ist. Noch wichtiger macht diese Kernbilder der Umstand, dass sie in den verschiedensten Hoden und auch

1) A. Z immerman $\mathrm{n}$ betrachtet in seinem Buche: „Die Morphologie und Physiologie des pflanzlichen Zellkernes" (Jena 1896) die durch Alkohol bewirkte einseitige sichelartige Anhäufung der Kernsubstanz als normalen Zustand, und hält diese Anhäufung für den Nucleolus. 
in Ovarien fast im ganzen Tierreiche allgemein beobachtet werden können.

Es unterliegt jedoch keinem Zweifel, dass die Formen der „Synapsis"-Stadien, wie wir sie gewöhnlich in den Schnitten fast aller Hoden treffen, stark entstellt sind, indem die eine Hälfte des Kernes meistens ganz leer elscheint, während die ganze Substanz des Kernes in der anderen Hălfte zusammengedrăngt ist.

Eine für meine Untersuchungen willkommene Ausnahme bildet der Salamanderhoden, in welchem die "Spermatocyten" keine solche auffallenden Entstellungen zeigen. Trotzdem lässt sich das Synapsis-Stadium hier bestimmt erkennen und da der Kern auch gross ist, bequem untersuchen.

In den Spermatocyten der meisten Tiere sieht man in diesem Stadium vom dichteren Teil des Kernes in den leereren Teil Chromatinschlingen hinüberreichen, so jedoch, dass die Schlingen die leere Kernhălfte nicht gleichmässig ausfüllen, sondern meistens sehr weit von der Oberfläche des Kernes zurückgezogen erscheinen. Im Salamanderhoden durchziehen die aus dem dichteren Teile ausgehenden Schlingen ganz gleichmässig die andere Hälfte des Kernes und füllen dieselbe ganz aus, sodass auch dieser Teil des Kernes nicht leer erscheint, wie es bei anderen Objekten der Fall ist.

Bei den Spermatocyten der meisten Tiere kann nur bei den in diesen leeren Teil hinüberreichenden Faden von einer guten Sichtbarkeit die Rede sein, wahrend die Analyse der die andere Hălfte ausfüllenden feinen, dichteren, oft homogen erscheinenden Formation ganz unmöglich ist. In den grossen Zellen des Salamanders dagegen ist auch dieser dichtere Teil analysierbar. Man kann sich überzeugen, dass das Synapsis-Stadium gleich nach dem oft erwähnten sternförmigen Stadium folgt. Dem Synapsis-Stadium folgt dann das Stadium des dicken Fadens, sodass also die Synapsis zwischen dem sternförmigen und dem Stadium des dicken Fadens eingeschaltet ist. Wie wir sehen werden, liegt darin auch die Erklärung für die Eigentümlichkeiten dieses Stadiums

Das Erkennen des Wesens dieses Stadiums beruht auf der Analyse des dichten Kernteiles, denn die klare Beobachtung des Fadens in der anderen Kernhälfte bereitet - wie erwăhnt nicht einmal bei ungünstigen Objekten Schwierigkeiten. Natürlich 
ist in diesem Teile des Salamander- „Spermatocytenkernes“ das Verhalten des Kernfadens und seine regelmässige Anordnung umso klarer beobachtbar. Der Faden bildet an dem der dichten Kernhălfte entgegengesetzten Teile sich regelmässig umbiegende Schleifen, d. h. der Faden endet hier nie frei. Wir erkennen in dieser Anordnung des Fadens die bekannte polare Erscheinung, mit dem Unterschiede aber, dass wahrend bei den gewöhnlichen Teilungen die polare Anordnung nur später, zur Zeit des vollständig ausgebildeten dicken Fadens auftritt, hier schon dann eine polare Anordnung zu sehen ist, wenn in der einen Hälfte des Kernes ein mitotischer Faden überhaupt nicht $\mathrm{zu}$ sehen ist. In dieser Halfte des Kernes können wir ein eigentümliches dichteres Gebilde treffen, welches den dichteren Ansammlungen der Synapsiskerne anderer Tiere entspricht (Taf. XXVII, Fig. 9).

Was geschieht nun mit dem Faden in dem dichteren Teile? Löst er sich vielleicht auf, oder rollt er sich so dicht zusammen, dass wir hier den Faden nicht mehr isoliert wahrnehmen können? Bei der Reifungsteilung der Salamanderhodenzellen kann festgestellt werden, dass nicht der letztere Fall vorliegt, dass in der dichteren Kernhalfte nicht von dichteren Windungen ein und desselben Kernfadens die Rede ist, sondern dass hier ein ganz besonderes Kerngebilde vorliegt, mit welchem der Faden verschmolzen ist.

In Taf. XXVII, Fig. 9 ist ein Stadium gezeichnet, welches aber nur einen Teil des Kernes vorstellt, in welchem das Erscheinen der dicken Fadenbildungen in der einen Hălfte eben wahrnehmbar ist und die andere Halfte die problematische dichtere Formation zeigt. So zeigen die beiden Kernhälften ein ganz verschiedenes Verhalten, welches den Synapsis-Formen anderer Tiere entspricht. Die dichte Formation entbehrt jeder Regelmassigkeit. Sie erscheint in sehr dünnen intensiv gefärbten Schnitten, wie aus der Abbildung ersichtlich ist, als unregelmässiges sternförmiges Gebilde, welches mit den dicken Fadenbildungen der anderen Hälfte in direktem Zusammenhang steht. Diese eigentümliche Einrichtung schien für den ersten Augenblick unerklärbar zu sein, erhielt jedoch auf Grund der vorangehenden eine Lösung. In der dichten Kernhălfte der Salamander- „Spermatocyte“ können wir nămlich erkennen, dass sie eigentlich das frühere sternförmige 
Stadium vorstellt. Das Bild, welches in den vorangehenden Stadien der Kern in seiner Gesamtheit zeigte, zeigt jetzt nur mehr die eine dichte Hälfte desselben. Hiermit gewinnen wir mit einem Male einen Einblick in die Erscheinung der Synapsis. Die eine Kernhalfte vertritt also ein früheres Stadium als die andere.

Dass diese sternförmigen Gebilde Kunstprodukte sind, ist vorläufig gar nicht wichtig. Wesentlich ist nur die Erscheinung, dass zu einer Zeit, wo in der einen Hälfte des Kernes die Bildung des dicken Fadens schon begonnen hat, die andere Hälfte noch in einem früheren Zustande verweilt.

Die Synapsis beruht also darauf, dass die Bildung des dicken Fadens nicht in dem ganzen Kerne gleichzeitig, sondern polar beginnt, d. h. dass die Bildung des Fadens an einer Stelle des Kernes beginnt und sich erst stufenweise weiter erstreckt. Die Stelle, an welcher die Entwicklung des Fadens beginnt, ist der Ort, an welchem auch noch spater nach Ausbildung des ganzen Fadens die regelmässigen Umbiegangen der Fadenschleifen wahrnehmbar sind. Solche spätere Bildungen sind bei Meves (Arch. f. mikr. Anat., Bd. 48, siehe oben) in Fig. 45 und 47 gezeichnet, aus welchen ersichtlich ist, dass die Stelle der Fadenumbiegungen nach den Centrosomen hin gerichtet ist.

Die polare Einrichtung entspricht dem in der Mitose allgemein auftretenden Verhalten. Die Art der Entstehung dieser Anordnung aber weist in der Reduktionsteilung auf eigentümliche Verhältnisse hin. Bei den gewöhnlichen Teilungen tritt der scharf umschriebene feine Faden im ganzen Kerne gleichmässig auf, zeigt charakteristische Biegungen, entbehrt jeder polaren Anordnung. Die polare Anordnung entsteht hier nach der Ausbildung des dicken Fadens und die Entwicklung des dicken Fadens, resp. das gleichmässige Dicker- und Kürzerwerden der neu aufgetauchten feinen Formation steht ausser Zweifel. Beider Reduktionsteilung ist erstens nirgends von dem Auftreten eines so scharf begrenzten Fadens wie bei den gewöhnlichen Teilungen die Rede, und zweitens scheinen die zuerst auftretenden Formationen noch viel dichter zu sein, als bei den gewöhnlichen Teilungen, besonders wenn man die oben diskutierten Kaliessigsäure-Bilder für lebenstreu hält. Auch der dicke Faden der Redultionsteilung ist ganz eigentümlich und besitzt noch in den spätesten Stadien keine glatten Konturen und ist meistens mit Fortsätzen versehen. Oft 
erhält man Bilder, in welchen der sich entwickelnde dicke Faden der Quere nach aus regelmässigen, nahezu quadratischen Bestandteilen zusammengefügt ist (Taf. XXVIII, Fig. 9 u. 10).

Die Entwicklung dieser dicken Faden bei der Reduktionsteilung beginnt also mit einer polaren Anordnung, was eigentlich auch damit übereinstimmt, dass die polare Anordnung auch bei den gewöhnlichen Teilungen erst mit dem dicken Faden auftritt; der genetische Zusammenhang des dicken Fadens mit den vorangehenden feinen Formationen ist aber nicht so einfach und klar, wie bei den gewöhnlichen Mitosen.

Bei der Reduktionsteilung ist, wie wir sehen, in der einen Hälfte des Kernes die Bildung des Fadens immer etwas weiter fortgeschritten, wie in der anderen Hälfte. So kann man nun in ein und demselben Kerne die Kombinationen verschiedener Stadien antreffen. Die häufigste besteht darin, dass der in der klareren Kernhälfte sichtbare Faden sich mit dem sternförmigen Stadium der anderen Kernhälfte verbindet. Es kann aber ebenso zu dem dicken Faden sich eine etwas feinere, gezackte, doch mehr fădige Formation gesellen, welche genetisch unmittelbar nach dem sternförmigen Stadium folgt. Dieses feine, schon fadenartige, mit Fortsätzen versehene Stadium, kann auch allein den ganzen Kern ausfüllen, was in $\mathrm{M}$ e ve s eben zitierter Arbeit (Fig. 44) abgebildet ist. Dieses dem dünnen Faden der gewöhnlichen Teilung entsprechende Stadium besitzt auch einen ganz eigentümlichen Charakter; da seine Stellung zwischen das sternförmige Stadium und das des dicken Fadens fällt, so vertritt auch diese Formation in der Tat den Mittelweg zwischen beiden; noch sehr unregelmässig, resp. mit vielen Fortsătzen versehen erscheint sie wie das frühere Stadium, aber sie hat auch schon etwas fadenartiges in ihrem Charakter, dem späteren Stadium entsprechend. Die Abweichung vom feinen, glatten Faden der gewöhnlichen Mitose ist aber so gross, dass sozusagen nur die gut bestimmbare Stellung des Stadiums ihre Zusammengehörigkeit ausser Zweifel stellt.

Inwiefern dieser mit Fortsätzen versehene feinfädige Knäuel der Wirklichkeit entspricht, inwiefern er für ein Kunstprodukt zu halten ist, dies kann ich an dieser Stelle nicht beantworten, denn die Deutung dieser Bilder ist viel komplizierter, als dass sie in dem Rahmen dieser allgemeinen Untersuchungen besonders 
herangezogen werden könnten. Ich wollte nur darauf hinweisen, dass das Wesen des Synapsis-Stadiums darin besteht, dass der Kernfaden bald mit dem sternförmigen Stadium, bald mit dem mehr feinfädigen Stadium kombiniert erscheinen kann. Kombinationen der dicken und feinen Faden sind in Taf. XXVIII, Fig. $8 \mathrm{a}, 10 \mathrm{zu}$ sehen.

Wir müssen uns daher die Synapsis-Kerne so vorstellen, dass die eine Hălfte des Kernes, diejenige, die das frühere Stadium vorstellt, sich nahher dem diffusen Verteilungszustande befindet, wăhrend in der anderen Hälfte des Kernes der Differenzierungsprozess weiter vorgeschritten ist. Die zwei Kernhalften sind auf diese. Weise auch im Leben physikalisch verschieden. Dieser verschiedene Zustand der beiden Kernhalften macht es begreiflich, dass die halbverschiedene Einrichtung dieser Kerne nach der Fixation in den meisten Fällen noch mehr übertrieben erscheint. Wir dürfen es uns auf keine Weise vorstellen, dass die eine Kernhälfte im Leben leerer wăre als die andere. Dies beweisen die peripherischen Osmiumbilder bei der Flemming schen Flüssigkeit, wo auch in diesen Stadien die Kerne bei allen Tieren gleichmässig ausgefüllt sind. Die physikalischen Verschiedenheiten in den beiden Hälften desselben Kernes machen es aber verständlich, dass nach den meisten Fixationen diese Verschiedenheit in noch auffallenderer Weise erscheint. Der dem früheren Entwicklungsstadium entsprechende homogenere Teil wird durch die meisten Fixationen noch mehr verdichtet und zieht hierdurch die schon differenzierten Fadenschlingen der anderen Kernhälfte zu sich hin; somit wird diese Kernhalfte leerer und die andere umso dichter. Noch auffallender wird dieser Unterschied in den gefärbten Präparaten, in denen der Kontrast der beiden Kernhälften durch die starke Färbung des dichteren Teiles noch mehr in die Augen sticht.

Der Umstand, dass in der Reduktionsteilung verschiedene Stadien der Fadenentwicklung in ein und demselben Kerne wahrnehmbar sind, kann in weiteren Untersuchungen noch gut verwertet werden, besonders zur Beurteilung der Reihenfolge der Erscheinungen.

Für unsere Betrachtungen war es nuir wichtig, festzustellen, dass auch bei der Reduktionsteilung die Fadenbildung in der diffus verteilten Kernsubstanz mit dem Auftreten neuer, ausser- 
ordentlich feiner Formationen beginnt. Die ersten Phasen erscheinen auch hier als ungemein feine und dichte Formationen, deren Charakter, die Brechungen und Biegungen der Formationen aber anders sind, als bei den gewöhnlichen Teilungen. Von einem scharf konturierten Faden, wie bei der gewöhnlichen Mitose, kann ebenso wenig in den ersten, wie in den spateren Phasen gesprochen werden. Es ist auch fraglich, ob diese sehr feinen Anfangsformationen in den Kaliessigsäure-Bildern als zusammenhängender Faden betrachtet werden können (Tafel XXVIII, Figur 1, 2, 5 a, 6, 7).

Wie ich es im Vorausgeschickten erläutert habe, ist es nicht ausgeschlossen, dass diese Formationen für lebendige zu halten sind. Wir dürfen aber nicht glauben, dass, wenn wir diese Formationen zweifellos für lebendig halten, die Entwicklung des Reduktionskernfadens hiermit klar gelegt sei. Den Zusammenhang dieser Bildungen mit dem Mevesschen feinfädigen Knäuel oder mit dem dicken Faden vermag ich hier einstweilen nicht zu entscheiden. Ohne weitere Untersuchungen wird das einfachste sein, anzunehmen, dass die Verhältnisse hier auch in den Hauptzügen mit dem Schema der gewöhnlichen Teilung übereinstimmen, bei welcher die schon einmal aufgetauchte feine Formation in continuo in den dicken Faden übergeht.

Ich kann aber nicht versaumen, auch auf solche Bilder hinzuweisen, welche dieser Annahme bei der Reduktionsteilung zu widersprechen scheinen. Bei der peripherischen Kaliessigsäure-Wirkung begegnete ich solche Kernbilder in welchen sich zu den Teilen des dicken Fadens körnige Formationen gesellen (Taf. XXVIII, Fig. 9a). Diese halbverschiedenen Kerne, welche auf den Gang der Entwicklung direkt hinweisen können, zeigen, dass der dicke Faden gepaart mit fein verteilten Formationen erscheinen kann, aus welchen der Faden notwendigerweise im weiteren sich ergänzen muss. Nach diesen Bildern zu urteilen, würde sich die primäre feine Formation auflösen und der dicke Faden sich wieder aus einer diffusen Verteilung herausbilden. An die Möglichkeit solcher Umänderungen dürfen wir umsomehr denken, als die direkte Entwicklung des Kernfadens aus vorher sichtbaren Formationen nach dem vorhergehenden keine prinzipielle Bedeutung mehr hat. Diese Fragen bedürfen und verdienen aber noch näherer Untersuchung. 
Ebenso wie bei der Reduktionsteilung ein scharf konturierter Kernfaden vom Anfange an fehlt, so weicht auch der dicke Faden wesentlich vom gewöhnlichen dicken Kernfaden ab, indem der dicke Reduktionskernfaden bei den meisten Fixierungen an der Oberfläche sehr lange Zeit Fortsätze zeigt. Im Durchschnitte erscheinen die Fäden regelmäßig vier-bis fünfeckig, an welchen Ecken diese charakteristischen Fortsätze entspringen. Die Figg. 45 und 47 von Meves und meine auf Taf. XXVIII befindliche Fig. 11 stellen ein und dasselbe Stadium vor, nur stellt meine Figur einen Schnitt vor, in welchem die dicken Fadenschlingen rein der Quere nach getroften sind; Zahl und Lagerungsverhältnisse der Schlingen sind hier genau wiedergegehen.

Die Fortsătze des Reduktionsfadens (Taf. XXVIII, Fig. 8 unten) verschwinden erst in den letzten Stadien, unmittelbar vor dem Beginne der zur Teilung führenden Bewegungen. Die Fortsätze könnten vielleicht als Verdichtungsstränge aufgefasst werden, durch deren Vermittlung die Kernsubstanz die diffuse Verteilung verlässt und zur Bildung des dicken Fadens schreitet. Hierdurch wäre auch die eben erwähnte Erscheinung erklärlich, dass die primäre Formation zunächst in diffuse Verteilung übergeht, und dass der dicke Kernfaden aus der diffusen Verteilung mit Hilfe dieser Konzentrationsstreifen entsteht.

\section{Bemerkungen über die Eikerne.}

Die Kerne der Eizellen waren es, in welchen die Reduktionsmitose und die Reifungserscheinungen zuerst systematischen Untersuchungen unterzogen wurden. Es ist interessant, dass diese Untersuchungen Resultate ergeben haben, deren Bedeutung die Beobachter noch damals nicht vermuten konnten. Nach einigen vereinzelten Beobachtungen beschrieben $B$ orn und $R$ ückert ausführlich bei den Reifungserscheinungen der Eizellenkerne sowohl die diffuse Verteilung des "Chromatins", als auch die Entwicklung des Kernfadens aus dieser diffusen Verteilung. Obwohl sie das gănzliche Verschwinden des "Chromatins" beschrieben und in Abbildungen wiedergaben, verteidigten sie trotzdem nicht nur das Prinzip der Kontinuitat des "Chromatins"; sondern $R \ddot{u} c k e r t$ verteidigte auch nach diesen Beobachtungen noch die Kontinuität der Chromosomen, für welche Kontinuität auch neuerdings Boveri in seiner obenerwähnten Arbeit sehr 
entschieden eintritt. $\mathrm{Ca}$ rn oy und $\mathrm{L}$ e br u n wurden dagegen den Tatsachen gerecht und bezweifelten schon das Erhaltenbleiben des Fadens bei den Reifungserscheinungen des Eizellen-Kernes. Auf Grund meiner Untersuchungen kann es als feststehend betrachtet werden, dass weder die bisher beschriebene feine Verteilung des "Chromatins" bei den Reduktionsteilungen der Eizellen, noch die selbständige Neubildung des Kernfadens spezielle Eireifungserscheinungen sind, dass vielmehr beide allgemeine mitotische Erscheinungen vorstellen. So hat sich in der Geschichte unseres Themas die Erscheinung wiederholt, dass gewisse Tatsachen von allgemein biologischer Bedeutung zuerst vereinzelt, als spezielle Erscheinungen beschrieben wurden, während man erst später ihre allgemeine Bedeutung erkannte. In derselben Weise wie auch die Furchung der Eizelle früher bekannt wurde und erst später sich ihre allgemeine Bedeutung als Zellteilung herausstellte, so wurde auch die diffuse Verteilung des „Chromatins", das Aufhören der Kontinuität desselben, die selbständige neue Entwicklung des Kernfadens bei den Eikernen früher beschrieben, bevor noch ihre allgemeine biologische Bedeutung erkannt worden war.

Natürlich müssen wir die Reifungserscheinungen des Keimbläschens, wenn wir ihre Zusammengehörigkeit mit den „Spermatocyten “ vor Augen halten, auch nur für das sehr protrahierte Anfangsstadium der Reduktionsmitose halten. Im ersten Stadium des Reifungswachstums der Ovogonien (Ovocyten der Autoren) ist die charakteristische einseitige Kernbildung (die Synapsis) eine ebenso konstante Erscheinung, wie bei den "Spermatocyten“. Die Ähnlichkeit dieser Stadien beim männlichen und weiblichen Kern, z. B. beim Meerschweinchen, ist so gross, dass, wenn man sie ausserhalb ihres Organes betrachten würde, man nicht entscheiden könnte, welcher einen Ovocyten- und welcher einen Spermatocyten-Kern vorstellt.

Gewisse Eikerne, wie z. B. die der Amphibien, erlangen, indem sie sich der grossen Masse des Plasmas anpassen, eine ungewöhnliche Grösse, und, wahrscheinlich im Zusammenhange mit dieser Vergrösserung, erscheinen in ihnen die mitotischen Vorgänge modifiziert. Ich möchte die Gelegenheit nicht vorübergehen lassen, wenn auch nur kurz auf einen Umstand hinzuweisen, der bei den an diesen grossen Eizellen beschriebenen Erschei- 
nungen auf die Vorgänge bei den "Spermatocyten" hinweist. In diesen Eizellen erscheint der aus der diffus verteilten Kernsubstanz sich entwickelnde Faden als ein mit Fortsätzen versehenes wie behaartes Gebilde, welches u. a. von B or n als „bürstenförmige Formation " bei Tritoneiern beschrieben wurde. Es ist nicht unmöglich, dass diese bürstenförmigen Anhănge den erwähnten langandauernden eigentümlichen Fortsätzen des Spermatocyten-Kernfadens entsprechende Bildungen sind. Die bürstenförmigen Formationen weisen auch klar darauf hin, dass auch hier von einem vom Anfange an scharf konturierten Faden keine Rede sein kann, welchen Umstand auch ich für den SpermatocytenFaden am meisten charakteristisch fand. Alles deutet darauf hin, dass der Faden bei der Reifungsteilung nicht nach dem Typus des gewöhnlichen Kernfadens sich entwickelt, sondern dass eine der Reduktionsteilung der Spermatogonien und Ovogonien gemeinsame bedeutende Modifikation vorhanden ist.

8. Bildung des Tochterkernes, Zerfall der Chromosomen und Ursprung der Karyosomen.

Der Ursprung und die Neubildung des Fadens aus einer diffus verteilten Kernsubstanz bat sich aus dem vorhergehenden als eine allgemeine Erscheinung herausgestellt. Weitere Forschungen über das Schicksal des Fadens resp. der Tochterchromosomen werden zur Bestätigung der Richtigkeit dieser Resultate auch von einer anderen Seite her überzeugende Beweise liefern.

Man könnte a priori denken, wie man es heutzutage gewöhnlich annimmt, dass der Übergang der Chromosomen in den Ruhekern und die Entstehung des Fadens aus dem Ruhekerne identische Erscheinungen sind, indem man die erstere nur als die umgekehrte Wiederholung der letzteren betrachtet. Nach dem Obigen habe ich es nicht nötig, besonders hervorzuheben, dass ohne die Kenntnis des ruhenden Kernes und der Entwicklung des Kernfadens auch diese Auffassung auf keinem konkreten Tatbestande beruht und nur als schematisierte Aufassung anzusehen ist. Meine Untersuchungs-Ergebnisse sprechen für eine andere Ansicht.

Die wichtigen Veränderungen, durch welche die Chromosomen den neuen Kern bilden, sind folgende: Sobald die schirmförmigen Gruppen der Chromatin-Schleifen ihre ständige Lage 
erreichen, gestalten sie sich schon in dieser Anordnung sofort um. Zuerst breiten sie sich aus und bilden gleichsam mit ihrem eigenen Körper die Wandung des neuen Kernes (Taf. XXVI, Fig. 17, 18, 19). In dieser oberflächlichen Lagerung wird bald ihre Färbung schwächer und sie verlieren auch ihre scharfen Konturen. Die Schleifen verharren lange in diesem Zustande, woran man auch das Stadium erkennen kann. Dies wird auch durch die Gestalt des Kernes erleichtert, weil die dem Zentral-Körper entsprechende Vertiefung lange wahrnehmbar ist. Daher sind die Tochterkerne von den alteren ruhenden Kernen leicht zu unterscheiden. Gewöhnlich findet man in den Teilungsnestern dicht nebeneinander vollständige Serien, in welchen das Schicksal der Chromosomen genau verfolgt werden kann. So konnte ich wahrnehmen, dass die Chromosomen bei der Entwicklung des Tochterkernes einfach zerfallen, auf kurzem Wege zugrunde gehen, d. h. in eine feine diffuse Verteilung übergehen.

Es stösst auf keine besonderen Schwierigkeiten den Gang des Verschwindens zu verfolgen. Der Zerfall der Chromosomen schreitet parallel mit der Abnahme der Färbung; so wie die Farbung der Chromosomen abnimmt, in dem Maße nimmt auch der Zerfall der Chromosomen zu (Taf. XXVI, Fig. 19). Sowohl die Abnahme der Farbbarkeit, als auch der Zerfall, geschieht nicht nur in der ganzen Länge der einzelnen Schleifen, sondern gleichseitig in sämtlichen Schleifen des Kernes (Taf. XXV, Fig. 10). Nur an der Stelle des ursprünglichen Poles in der Năhe der Vertiefung des Tochterkernes ist der Zerfall vielleicht etwas weiter vorgeschritten als in den übrigen Teilen der Schleifen. Dies ist aber im ganzen wenig auffallend. Die Chromosomen zeigen bis zu ilhrer gänzlichen Zertrümmerung die polare Anordnung, welche sie vom Tochtersternstadium geerbt haben. Der allmăhliche Zerfall scheint lange $\mathrm{zu}$ dauern, was man aus der Hăufigkeit dieser Formen schliessen darf. Diese langdauernden, eine polare Anordnung zeigenden Kernbilder konnten auch zur Annahme der Rablschen Theorie von der polaren Einrichtung der Ruhekerne führen. Da aber das vollständige Zugrundegehen der Chromosomen keinem Zweifel unterliegt, so kann von dem Erhaltenbleiben dieser polaren Anordnung keine Rede sein.

Es muss betont werden, dass alle polaren Einrichtungen nur mit der eigentlichen Mitose, entweder mit dem Anfange 
oder dem Ende derselben zusammenfallen, bei dem Ruhekerne aber gar nicht zur Beobachtung kommen. Sie bedeuten ja eben schon ein sehr vorgeschrittenes Stadium der zur Mitose sich anschickenden Kerne, indem sie bei beiden Mitosen bei der. gewöhnlichen, wie bei der Reduktionsmitose erst mit der Ausbildung des dicken Fadens auftreten.

Camillo Schneider zeichnet auf Seite 88 seines Lehrbuches der vergleichenden Histologie einen Tochterkern aus den grossen Spermatogonien vom Salamander, in welchem die zerfallenden Chromosomen mit ihrer polaren Anordnung erkannt werden können (Vergl. Taf. XXV. Fig. 10, welche ungefähr dasselbe Stadium vorstellt). Es wiederholt sich hier der Omstand, welcher bei den Kernuntersuchungen oft angetroffen werden kann, dass zur Demonstration der Strukturen des ruheuden Kernes der Autor ein Kernbild auswählt, in welchem womöglich etwas sichtbar ist, ohne die Bedeutung des Zustandes in Erwägung zu ziehen.

Bei fixiertem Material sieht der Zerfall der Chromosomen in den Spermatogonien so aus, als ob sie einfach in verschiedene grosse Bruchstücke zerlegt würden. Parallel mit dem Zerfall erscheint dann die bisher fehlende Grundsubstanz des Kernes, und je weiter der Zerfall der Chromosomen vorgeschritten ist, desto dichter wird die Grundsubstanz, die sonach direkt dem Zugrundegehen der Chromosomen ihre Entstehung verdankt. Wir sehen aus all diesem, dass hier nirgends von einer mit der Entwicklung des Fadens vergleichbaren, umgekehrten Erscheinung die Rede sein kann. Die Entstehung des Fadens ist ein langwieriger und komplizierter Prozess, während die Umwandlung der Tochterchromosomen zu dem Tochterkern ein sehr einfacher Vorgang zu sein scheint. Die direkte, diffuse Verteilung der ererbten Kernsubstanz der Chromosomen vollzieht sich in den Tochterkernen gleichsam vor unseren Augen. Die fixierten Bilder darf man aber deshalb auch in diesen Fällen nicht für die treue Wiedergabe des Lebenden betrachten. Wenn wir in den fixierten Bildern sehen, dass die Chromosomen in Körnchen und Schollen zerfallen, müssen wir natürlich wieder in Betracht ziehen, dass diese, wie im Ruhekerne, eigentlich auch Fallungskörnchen sein können. Natürlich ändert auch dieser Umstand an dem Wesen der Sache nichts, sondern weist nur darauf hin, dass die Substanz der Chromosomen in eine sehr feine Verteilung übergeht, woraus dann die Körnchen und Schollen durch die Fixation ausgefällt werden. (Taf. XXVI, Fig. 17.) 
Wenn also in den Tochterkernen die Chromosomen vollständig verschwinden, woher kommen dann die Karyosomen? Man könnte denken, dass, obwohl die Chromosomen zweifellos zerfallen, wenigstens Teilchen und Stücke derselben in den Karyosomen erhalten bleiben, die dann wenigstens in beschränkter Form die Kontinuităt des Chromatins vermitteln würden. Ich muss aber betonen, dass die Bilder des Zerfalles der Chromosomen so deutlich sprechen, dass auch von dieser Annahme keine Rede sein kann. Alle Chromosomen zerfallen gănzlich und so gleichmässig, dass im Kerne nirgends vom Erbaltenbleiben einzelner Chromosomenpartien gesprochen werden kann. Wenn das Erhaltenbleiben einzelner Chromosomenpartien tatsächlich bestände, würde deren Wahrnehmung auf keine Schwierigkeiten stossen. Dass der Zerfall der Chromosomen und die Entwicklung der Karyosomen keine direkt zusammenhängenden Erscheinungen sind, können auch die karyosom freien grossen Kerne beweisen, in welchen nach dem vollständigen Zugrundegehen der Chromosomen überhaupt keine Karyosomen sich bilden. Es besteht eigentlich bei der Entwicklung eines jeden Kernes ein frühes Stadium, in welchem noch keine Karyosomen und auch keine Nukleolen vorhanden sind. Die Karyosomen tauchen so auf, wie die Nukleolen, also erst später. Die Karyosomen treten also im ruhenden Kern ebenso als neue Formationen auf, wie die Chromosomen bei der Mitose; sie stehen mit dem Verschwinden der Chromosomen in keinem direkten Zusammenhange. Erst mit dem Verschwinden der Chromosomen entwickelt sich die Grundsubstanz des Kernes und aus dieser Grundsubstanz entwickeln sich nachträglich wieder von neuem die Karyosomen. Interessant ist es, dass die Karyosomen gewöhnlich erst nach einer gewissen Verkleinerung des Kernes auftreten. Die Tochterkerne sind im Anfange während des Zugrundegehens der Chromosomen auffallend gross; dann mit der Ausbildung der Karyosomen wird der Ruhekern kleiner. Damit stimmt auch der Umstand, dass, wenn es nicht zur Karyosomenbildung kommt, die Kerne gross bleiben.

Wahrscheinlich geht diese Erscheinung Hand in Hand mit der zum Zerfalle nötigen Wasseraufnahme, ebenso wie das Kleinerwerden der Kerne und die Entstehung der Karyosomen mit Wasserverlust verbunden ist. 
Die Kerne der kleinen Nervenzellen, der Neuroblasten sind karyosomenreich, die grossen Kerne der entwickelten Nervenzellen enthalten keine Karyosomen. Dieselbe Umwandlung kommt im Kern der Spermatogonien beim Salamander vor, in welchen die grossen Spermatogonien meistens keine Karyosomen enthalten, wie sie sich aber stufenweise kleiner werdend zu kleinen Spermatogonien umwandeln, werden auch die Kerne immer reicher an Karyosomen. Die grossen Kerne der Săugetier-Eizellen sind ebenfalls frei von Karyosomen. Es erheischt, wie ich glaube, noch eine weitere Untersuchung, ob die vielen Kernkörperchen, z. B. der Eizellen der Amphibien, mit Karyosomen, oder mit Nukleolen vergleichbar sind, oder aber besondere Bildungen darstellen. Ich halte es für wahrscheinlich, dass sie mit meinen Karyosomen nicht in Zusammenhang zu bringen sind.

Wir haben keinen Grund daran zu zweifeln, dass die Substanz der Karyosomen mit der Substanz der Chromosomen identisch ist. Beide sind aller Wahrscheinlichkeit nach nur zwei verschiedene Formen einer und derselben Substanz. Die Entstehung und das Schicksal der beiden ist ihrem Wesen nach gleich. Beide Formationen entstehen aus diffuser Verteilung und gehen unter gewissen Umständen wieder in diffuse Verteilung über.

Die Karyosomen können als Depots der Chromatinsubstanz im ruhenden Kerne betrachtet werden, die sich dann bei der Mitose der Grundsubstanz anschliesst, aus welcher dann der Faden sich ausschliesslich entwickelt.

\section{Nukleokrystallin.}

Wenn wir nach dem Wesen des Ruhekernes forschen, so gelangen wir zu dem Resultate, dass von allen Teilen des Kerns der wichtigste weder die Karyosomen noch die Nukleolen sind, sondern die Kernflüssigkeit ist. Die Karyosomen sind zwar häufige, jedoch keine beständigen Bestandteile des Kernes, ein noch weniger beständiger Bestandteil ist der Nukleolus. Es bleibt also als das wesentlichste im ruhenden Kerne die Kernflüssigkeit. Auch die Entwicklung des Rubekernes ist ja mit der Entstehung der Kernflüssigkeit gleichbedeutend. Die Kernflüssigkeit erscheint bei unseren heutigen stärksten Vergrösserungen bomogen, was natürlich nicht ausschliesst, dass jenseits dieser Vergrösserungen sie noch bestimmte Formationen enthält. Noch weniger 
darf man daraus auf physikalische oder chemische Homogenität schliessen.

Die Wahrheit besteht darin, dass die Kernsubstanz in der Kernflüssigkeit im scheinbar homogenen Zustande so fein diffus verteilt ist, dass sie nicht als besondere Formation wahrgenommen werden kann. Hieran können wenigstens prinzipiell auch die Anhănger der strukturellen Anschauungen k keinen Anstoss nehmen, die sämtlichen gegenwärtig angenommenen Strukturen werden aber durch diesen Umstand vollständig ausgeschlossen. Viel heikler ist die Frage, ob man von lösungsähnlichen Zuständen sprechen darf, in welchem Falle parallel mit diesen auch das Auftreten der Chromosomen mit einer Kristallisation verglichen werden könnte.

Nach den neueren Angaben der physikalischen Chemie spielt eben ein lösungsähnlicher Zustand im organischen Leben eine grosse Rolle. Auf diese Weise ist auch die Möglichkeit bedeutend grösser, dass dem lösungsähnlichen Zustande auch im Leben des Kernes eine besondere Bedeutung beizulegen sei, und so gewinnt auch die Vergleichung der Entstehungsweise des Fadens mit einem Krystallisationsvorgang mehr Grund.

Diese Verhältnisse berührte ich hier hauptsächlich deshalb, um eine mir sehr nötig erscheinende neue Benennung năher zu begründen. Das Wort "Chromatin" bildete schon bisher ein grosses Hindernis bei der richtigen Erklärung der Erscheinungen, indem es sich nur mit den geformten Teile der Kernsubstanz deckt, die in diffuser Verteilung befindlichen dagegen nicht nur nicht in sich schliesst, sondern was schlimmer ist, die ungeformten Teile der ererbten Kernsubstanz vollkommen ausschliesst.

Auf die hieraus entstandenen Missverständnisse näher hinzuweisen ist nicht notwendig. Flemming selbst wollte ja mit seinem "Chromatin" nichts anderes andeuten, als die bekannte auffallende Färbbarkeit dieser Teile des Kernes, welche auffallende Färbbarkeit nach unserem heutigen Wissen nur so aufgefasst werden kann, dass in diesen Gebilden die Kernsubstanz sich in dichterem Zustande befindet. Die Kerne, in welchen keine Karyosomen sich befinden, sollten nach dieser Benennung auch kein "Chromatin" enthalten. Der Widerspruch liegt auf der Hand.

Vom histologischen Gesichtspunkte aus haben wir also ein Wort notwendig, welches die Möglichkeit der zweierlei Zustănde 
der Kernsubstanz zulässt und keinen speziellen chemischen Begriff prăjudiziert. Nach den obigen Auseinandersetzungen möchte ich die Benennung „Nukleokrystallin“ empfehlen.

Das Nukleokrystallin ist also ein weiterer Begriff, als das „Chromatin“, welches sich nur auf die sichtbaren morphologischen Teile bezieht, wăhrend das Nukleokrystallin ebenso auf diese, wie auch auf die in diffuser Verteilung sich befindliche Substanz bezogen werden kann.

Wir können also sagen, dass der Tochterkern eine gewisse Masse geformten Nukleokrystallins erbt, die zuerst in diffuse Verteilung übergeht. Die Entwicklung des Kernes kann als die Umformung des geformten Nukleokrystallins zu einem Flüssigkeitstropfen betrachtet werden, in welchem das Nukleokrystallin sich in einem gewissen diffusen, lösungsähnlichen Zustand befindet.

Der Zweck des lösungsähnlichen Zustandes kann so aufgefasst werden, dass eben in diesem Zustande die chemischen Prozesse für die Vermehrung der ererbten Substanz am besten stattfinden können. Das Prinzip "Corpora non agunt, nisi soluta"6 scheint hier Geltung zu haben.

In vielen ruhenden Kernen kann, meistens mit dem Kleinerwerden derselben, ein Teil des Nukleokrystallins sich ausscheiden, in welchem Falle dièser Teil in Gestalt der ,Karyosomen" erscheint, die als Depots des Nukleokrystallins im Ruhekerne angesehen werden können. Der übrige Teil des Nukleokrystallins bleibt gelöst. In den grossen Kernen ist die ganze Substanz gelöst und spielt wahrscheinlich in der chemischen Funktion des Kernes eine wichtige Rolle. Gerade in den grossen Kernen, wie z. B. in denen der grossen Spermatagonien, in welchen das gesamte Nukleokrystallin in lösungsähnlichem Zustande ist, können wir auch lebhaftere Funktionen vermuten, umsomehr als auch die bekannte polymorphe Gestalt dieser Kerne auf lebhaftere Aktionen hindeutet. Die mit der Mitose beginnende lebhaftere Funktion ist auch mit einer Auflösung der Karyosomen verbunden und es können auch unmittelbar vor der Mitose polymorphe Gestaltungen als Zeichen lebhafterer Tätigkeit auftreten.

In dem sich zur Mitose anschickenden Kern vermengt sich dann das verteilte Nukleokrystallin der Karyosomen mit dem schon in Verteilung gewesenen Nukleokrystallin des Rubekernes, um schliesslich einheitlich im Kernfaden sich auszuscheiden. 
Da infolge der Ausscheidung die ganze Masse des Nukleokrystallins individualisiert wird, endet auch die Individualităt des Kernes. Im ruhenden Kerne, in der chemischen Werkstätte der Neubildung des Nukleokrystallins kann der lösungsähnliche Zustand als eine notwendige Bedingung betrachtet werden. Zur reinen Ausscheidung und genauen Verteilung des Nukleokrystallins scheinen dann die präzis geformten krystallähnlichen Gebilde der Chromosomen berufen zu sein. Ob wir diese Vergleichung der Erscheinungen für mehr oder weniger berechtigt halten, oder nicht, die Benennung Nukleokrystallin kann, so meine ich, einen guten Dienst zur Vermeidung weiterer Missverständnisse leisten.

\section{Zusammenfassung und Schluss.}

Der wichtigste, der allein beständige Bestandteil des lebenden Kernes ist die Kernflüssigkeit, des fixierten Kernes die Grundsubstanz. Die Kernflüssigkeit ist bei unseren heutigen Vergrösserungen homogen; sie erscheint auch bei der nichtfällenden Osmiumwirkung homogen, hingegen bei sïmtlichen fällenden Fixationen aus ausgefällten Körnchen und Schollen bestehend.

In der Kernflüssigkeit können zweierlei Körperchen. erscheinen, die Nukleolen und die von mir mit dem Namen Karyosomen oder Nukleosomen genannten Bildungen.

Nicht nur die Nukleolen, sondern auch die Karyosomen liegen in der Kernflüssigkeit isoliert, d. h. beide Körperchen bilden keinen Bestandteil etwaiger Strukturen. Keine der bisherigen Strukturtheorien der Kerne hat Berechtigung. Die Benennungen, Lanthanin“, „Linin“, ,Paralinin“, „Oedematin“, „Pyrenin“, „Amphipyrenin“ etc., können nur zu falschen Vorstellungen Anlass geben und sind gănzlich zu vermeiden.

Die Karyosomen und Nukleolen sind scharf voneinander $\mathrm{zu}$ trennen. Sie sind sowohl ihrer Form und Substanz, als auch ihrer Entwicklung und ihrem weiteren Verhalten nach von einander verschieden.

Die Substanz der Karyosomen deckt sich mit dem Begriff des "Chromatins"; die Substanz der Nukleolen steht nach allen Erfahrungen mit fettartigen Stoffen in nahem genetischen $\mathrm{Zu}-$ sammenhange. 
Die Nukleolen erscheinen von ihrem ersten Auftreten bis zu ihrem Verschwinden als kuglige Gebilde, während die Karyosomen nie regelmässig rund und oft stäbchenförmig erscheinen.

Karyosomen und Nukleolen können auch in ein und demselben Kerne vorkommen, oft ist aber nur eine Art dieser Körperchen vorhanden; es ist ein gewisser Zusammenhang zwischen der Grösse des Kerns und dem Vorhandensein beiderlei Körperchen nachzuweisen; grosse, ausgebildete Kerne sind meistens karyosomenfrei und enthalten nur einige Nukleolen. Die kleineren Kerne hingegen sind karyosomenreich.

Die wichtigste Erscheinung beim Beginne der Mitose ist, dass sämtliche vorher vorhandene Körperchen in eine diffuse Verteilung übergehen. Die Nukleolen verschwinden in dem sich zur Mitose anschickendem Kerne einfach sich immer mehr verkleinernd ohne besondere Erscheinungen. Die Karyosomen zeigen dagegen im Beginne der Mitose charakteristische Umwandlungen: sie verbreitern sich in der Wachstumsperiode der Mitose, dann werden sie verzweigt und vakuolisiert, später verschwinden sie gänzlich.

Bei beiden Teilungsarten entsteht der Faden als Neubildung und nimmt seinen Ursprung in beiden Fällen aus der in der Kernflüssigkeit diffus verteilten Kernsubstanz mit unendlich feiner Anfangsformationen.

Nach der diffusen Verteilung der Karyosomen beginnt die Bildurig des mitotischen Fadens. Die neu auftauchende feine fädige Formation entwickelt sich bei den gewöhnlichen Teilungen ohne weiteres zu einem dicken Faden. Bei den Reduktionsteilungen ist die auftauchende Formation noch dichter, als bei den gewöhnlichen Teilungen, und die Erscheinungen weisen auf erhebliche Unterschiede zwischen beiden Teilungen hin. Das auffallendste ist, dass der sich entwickelte Faden bei der Reduktionsteilung nicht so glatt und rein konturiert erscheint, wie bei den gewöhnlichen Teilungen.

Das Dickerwerden der dünnen Fadenknäuel ist nur die Fortsetzung jener allmählich fortschreitenden ersten Entwicklung.

Weder in dem Ruhekerne, noch in dem sich zur Mitose anschickenden Kerne ist eine Polarität nachweisbar; diese erscheint erst sehr spät, nach der Ausbildung der dicken Fadenschleifen. 
Die Chromosomen geraten in den Tochterkernen wieder in denselben diffus verteilten Zustand, aus welchem sie ihren Ursprung nahmen; die Art und Weise dieser diffusen Verteilung aber hat mit der Entwicklung des Fadens nichts gemeinsames und die Bildung der Tochterkerne ist nicht als die umgekehrte Wiederholung der Fadenentwicklung aufzufassen.

Die Chromosomen gehen bei der Bildung der Ruhekerne gänzlich durch Zerfall zugrunde. Der Ruhekern verdankt seine Entstehung dem Zerfall der Chromosomen. Dieser Zerfall der Chromosomen ist ein vollständiger und führt zur Bildung der Kernflüssigkeit, sodass auch in gewisser Hinsicht von einer Auflösung der Chromosomen gesprochen werden kann.

Die Karyosomen ebenso wie die Nukleolen sind im Ruhekerne Neubildungen, welche mit keiner anderen vorher sichtbaren Formation in direktem morphologischen Zusammenhange stehen. Die Tochterkerne sind wăhrend der Auflösung der Chromosomen relativ gross (Wasseraufnahme). Bleibt diese Grösse erhalten, so entstehen die grossen karyosomfreien Kerne. In vielen Kernen bilden sich die Karyosomen aus, was mit Verkleinerung des Kernes (Wasserverlust) verbunden ist.

Ich empfehle als Benennung für die in den Chromosomen ererbte Substanz den Namen Nukleokrystallin, welcher Ausdruck die geformte sowohl wie die in diffuser Verteilung befindliche Substanz umfassen kann und keinen chemischen Begriff präjudiziert.

Die Karyosomen können als Depot für einen Teil des Nukleokrystallin der Ruhekerne betrachtet werden, während ein anderer Teil der ererbten Substanz in diffuser Verteilung sich in der Kernflüssigkeit befindet. Im karyosomfreien Kerne ist die ganze Masse des ererbten Nukleokrystallins in der Kernflüssigkeit verteilt.

Die „Spermatocyten" der Autoren sind nicht als Ruhekerne aufzufassen; sie stellen vielmehr die ersten Phasen der Reduktionsteilung dar. Korrekter wäre nur von sich zur Reduktionsteilung anschickenden Spermatogonien zu reden.

Die sternförmigen Formationen der "Spermatocyten" des Salamanderhodens in der zentralen Wirkungssphäre der fixierenden Flüssigkeiten, die bisher als Ruhekerne aufgefasst wurden, sind als aus dem Zusammenfliessen der Kernsubstanz entstandene Kunstprodukte zu deuten und stellen ein Stadium der Mitose vor. 
Die „Synapsis" findet darin ihre Erklärung, dass in der Reduktionsmitose die Bildung des Fadens nicht wie in der gewöhnlichen Mitose im ganzen Kern zu gleicher Zeit und gleichmässig stattfindet, sondern dass dieser Vorgang von einem Teile des Kernes ihren Ausgang nimmt und von dort aus allmählich fortschreitet. Die dichtere Hälfte dieser Kerne stellt immer ein früheres, die hellere immer ein späteres Stadium der Mitote vor.

Das Ziel dieser Arbeit war, die allgemeinen Erscheinungen des ruhenden Kernes und der Mitose in ein schon lange entbehrtes einheitliches Bild zusammenzufassen. Die Kritik der Fixations-Methoden, die erneute Untersuchung der lebendigen Kerne rückten die Verhältnisse derartig in neues Licht, dass ich in dieser Arbeit auf die einzelnen Daten und Untersuchungen über Kernstruktur nicht näher eingegangen bin; dies wäre nicht nur ein undankbares sondern zum Teile auch ein überflüssiges Unternehmen gewesen. Ich berührte nur insofern einzelne Arbeiten, als sie sich zur Beleuchtung des Themas besonders darboten.

Die nähere Berücksichtigung der Literatur hätte notwendigerweise zu viel Polemik zur Folge gehabt. Mein Ziel war, die Frage durch einige eingehend untersuchte Beispiele zu beleuchten. Der heutige Stand der Frage brachte es mit sich, dass ich nur dann eine nützliche Arbeit vollbringen zu können glaubte, wenn ich, anstatt die Ansichten anderer fortwährend anzugreifen und zu untergraben, eher ein wenig aufzubauen bestrebt war. Wenn es mir gelungen sein sollte ein festeres Fundament zu finden, so werden ja die Luftschlösser der strukturellen Theorien ohnehin von selbst zusammenfallen.

Es wird Aufgabe weiterer Detailuntersuchungen sein, aus der Literatur das Wertvolle vom Wertlosen zu sondern und der bleibenden Verdienste gerecht zu werden. Die Verhältnisse der Karyosomen, ihr Werden und Vergehen, die Entstehung und Auflösung des mitotischen Fadens drängen sich alle auf Grund einer genauen Kritik der Bilder lebender Kerne und der Wirkung der Fixierungen zu weiteren Untersuchungen von selbst auf. Von den an anderen Objekten ausgeführten weiteren Untersuchungen darf ich die Bestätigung meiner Ergebnisse erhoffen. 
Erklärung der Abbildungen auf Tafel XXIV_XXVIII.

\section{Tafel XXIV.}

Enthält die Bilder lebender Kerne in der eigenen Flüssigkeit des betreffenden Gewebes untersucht und einige Essigsäure-Reaktionen. Sämtlich bei guter Mittagsbeleuchtung mit Leitz hom. Im. 1/12, Komp.-Ok. 4, sofort sorgfältig gezeichnet.

Fig. 1. Kern einer kleinen Spermatogonie. Salamander. Eigene Flüssigkeit.

Fig. 2. Leberzellenkern. Triton. Eigene Flüssigkeit.

Fig. 3-4. Darmepithelzellenkerne. Triton. Eigene Flüssigkeit.

Fig. 5. Grosse Spermatogonie. Salamander. Eigene Flüssigkeit.

Fig. 6. Dieselbe Zelle (5) nach Zusatz von $1^{\circ} \cdot$ o Essigsäure.

Fig. 7. Darmepithelzellenkern vom Triton (vergl. 3-4) nach Einwirkung von $1^{\circ} \%$ Essigsäure.

Fig. 8. Salamanderhode. Eigene Flïssigkeit. Isoliert schwimmende Kerne zwischen den Spermatiden.

Fig. 9u.10. Grosse Spermatogonien. Salamander. Eigene Flüssigkeit.

Fig. 11. Blasenepithelzelle. Triton. Eigene Flüssigkeit.

Fig. 12. Blasenepithelzelle. Triton. 1\% Essigsäure.

Fig. 13. Darmepithelzellenkern einer Raupe. Eigene Flüssigkeit.

Fig. 14. Blasenepithelzelle. Eidechse. Eigene Flüssigkeit.

Fig. 15. Dieselbe Zelle (14) nach Zusatz von $5^{\circ} \%$ Essigsäure.

Fig. 16-18. Kerne aus dem Mesenterium, 19 aus der Lunge des Tritons. Eigene Flüssigkeit. Die Formationen sind im Leben nicht so deutlich wie in den Abbildungen.

\section{Tafel XXV-XXVIII.}

Sämtliche Abbildungen (mit Ausnahme von Taf. XXVII, Fig. 1) sind zur Erleichterung der Übersicht und der Vergleichung der Bilder mit ein und derselben Vergrösserung, Leitz hom. Im. 1/12 bei ausgezogenem Tubus, unter Benutzung der Camera lucida, auf den Arbeitstisch projiziert, mit möglichster Genauigkeit gezeichnet. Zur Zeichnung erwies sich die Kombination des Tagesund des elektrischen Lichtes vorteilhaft, mit welchen zwei Beleuchtungsarten sowohl die vollkommenste Schärfe des Bildes, als auch die gute Sichtbarkeit des Bleistiftes erreicht werden konnte und zwar so, dass das Objekt durch das elektrische Licht, der Bleistift durch das Tageslicht beleuchtet wurde. Abbildung Taf. XXVII, Fig. 1 mit eingeschobenem Tubus und auf die Höhe des Objekttisches projiziert gezeichnet, also im Vergleich zu den übrigen weniger vergrössert.

\section{Tafel XXV.}

Grosse Spermatogonien. Salamanderhoden.

Fig. 1-5. Zeigen verschiedene feine Nuancen der Fällungsformen der Kernflüssigkeit nach Einwirkung von Kaliessigsäure. KupferhämatoxylinFärbung. 5 a u. b aus zwei Kerne gezeichnet. 
Fig.6-7. Schon etwas angewachsene Kerne grosser Spermatogonien mit eigentümlichen bizarren Formationen, welche an Stelle der früheren feinkörnigen Fällungen erscheinen. Frster Schritt zur Mitose. Nur die gut wahrnehmbaren Formationen sind gezeichnet. Daher erscheinen die Kerne heller als im Präparate, in welchem sie wegen der übereinander liegenden Formationen dunkler and dichter strukturiert sind. Kaliessigsäure. Cuprumhäm.

Fig. 8a a. 8b. Zwei Kerne aus der peripherischen Wirkungszone der Flemmingschen Flüssigkeit, Cuprumhäm.

8a) Stadium unmittelbar vor dem Erscheinen des Kernfadens.

8b) Allerfeinster Kernfaden, mit charakteristischen Brechungen und ohne jede polare Anordnung. Nur ein sehr kleiner Teil der Fadenwindungen ist gezeichnet.

Fig. 9. Etwas älterer Kernfaden als in Fig. $8 \mathrm{~b}$. Auch hier ist nur ein kleiner Teil des Fadens gezeichnet.

Fig. 10. Zerfall der Chromosomen im Tochterkern. Kaliessigsäure. Cuprumhäm.

Fig. 11. Flemmingsche Flüssigkeit. Peripherische Wirkung.

a) Gewöhnlicher homogener Kern mit einigen Nukleolen.

b) Ein seltener Zustand mit vielen Nukleolen und karyosomartigen Körperchen.

Fig. 12. Vom jungen Salamander. Flemmingsche Flüssigkeit. Ausgeprägte Osmiumwirkung. a) Ruhekern. b) Erste Spuren des Fadens.

\section{Tafel XXVI.}

I. Mittelgrosse Spermatogonien vom Salamander (1-4).

Fig. 1. Kern mit dem Charakter der kleinen Spermatogonien. Erscheinen der Karyosomen. Kaliessigsäure. Cuprumhäm.

Fig. 2. Stadium der bizarren Formationen. Kaliessigsäure. Cuprumhäm. Peripherische Wirkung.

Fig. 3. Flemmingsche Flüssigkeit. Cuprumhäm. Peripherische Wirkung.

a) Erste Spuren des feinen Fadens mit noch einigen zerfallenden Karyosomen.

b) Erste Spuren des Fadensin einem schon homogen gewordenen Kern.

Fig. 4. Eigentümliche Formationen, welche von den bizarren Formationen zur Entwicklung des dicken Fadens führen. Kaliessigsäure. Cuprumhäm.

II. Kleine Spermatogonien vom Salamander. (5-19.)

Fig. ó-7. Ruhende Kerne kleiner Spermatogonien. Verschiedenes Aussehen der Kernflüssigkeit resp. der Grundsubstanz. Karyosomen.

Fig. 5. Periphere Wirkung derFlemmingschen Flüssigkeit. Homogene Grunds.

Fig. 6. Zentrale Wirkung der Flemmingschen Flüssigkeit. Beide mit Cuprumhäm. gefärbt. Körnige, substanzarme Grunds.

Fig. 7. Kaliessigsäure. Cuprumhäm. Körnige Grundsubstanz.

Fig. 8. Kaliessigsäure. Cuprumbäm. Periphere Wirkung. a) Sich zur Mitose anschickender Kern, unmittelbar daneben zum Vergleich ein Ruhekern (b). Im anwachsenden Kern (a) Zerfall der Karyosomen. 
Fig. 9. Einige Formationen aus einem sich zur Mitose anschickenden Kern bei zentraler Wirkung der Kaliessigsänre.

Fig. 10. Kaliessigsäure. Cuprumhäm. Sich zur Mitose anschickender Kern. Es wurde nur ein Teil der Formationen gezeichnet.

Fig. 11. Dasselbe Stadium. Periphere Wirkung der Flemmingschen Flüssigkeit. Zerfall der Karyosomen.

Fig. 12. Bizarre Formationen nach zentraler Wirkung der Flemmingschen Flüssigkeit. Cuprumhäm. a) Die zwischen den sternförmigen Formationen sichtbaren feinen Fädchen erinnern sehr an die ersten Spuren des Fadens der grossen Spermatogonien. b) Ein sehr kleiner Teil eines sich in ähnlichem Stadium befindlichen und ähnlich behandelten Kernes.

Fig. 13. Kaliessigsäure u. 14 Flemmingsche Flüssigkeit. Rechtwinkelige Brechungen zeigende Fadenbildungen. Sämtliche Figuren zeigen nur einen kleinen Teil des Kernes.

Fig. 15. Typisch vorkommende, schwer zu deutende Bilder; dicke Fadenbildungen, zwischen welchen noch dünnere oder auch bizarre Formationen zu finden sind. Kaliessigsäure. Periphere Wirkung. Cuprumbäm.

Fig. 16. Teile des dicken Fadens ohne jede andere Formation. Kaliessigsäure. Cuprumhäm.

Fig. 17. Tochterkern. Zerfall der Chromosomen. Bei einer Einstellung gezeichnet, in welcher noch Spuren der polaren Anordnung zu erkennen sind, sonst erscheint der ganze Kern aus Trümmern und Brocken bestehend wie die Ruhekerne.

Fig. 18. Relatives Grössenverhältnis eines Tochterkernes und der letzten Stadien eines Tochtersternes. Tochterkern wie auch in Fig. 17 relativ gross, wahrscheinlich durch reichliche Wasseranfnahme aufgequollen, womit das Zugrundegehen der an der Oberfläche sich ausbreitenden Chromosomen parallel zu gehen scheint.

Fig. 19. Bildung des Tochterkernes, in drei aufeinander folgenden Stadien, auch im Schnitte nebeneinanderliegend. Von den paarigen Tochterbildern der Einfachheit halber nur je eines gezeichnet. Abnabme der Färbungsintensität und damit parallel gehend Zerfall der Chromosomen. (Behandlung in Figg. 17, 18, 19 wie in 16.)

\section{Tafel XXVII.}

Prophasen der Reifungsteilungen, sogenannte „Spermatocyten" des Salamanders nach Wirkung der Flemmingschen Flüssigkeit. Vergleiche Taf. XXVIII.

Fig. 1. Im Vergleich mit sämtlichen übrigen Figuren weniger vergrössert. Demonstriert erstens die für meine Folgerungen ungemein wichtig gewordene Tatsache, dass die angeblich homogenisierende peripherische Wirkung der Flemming schen Flüssigkeit nur bei den "Spermatocyten" (c. d.) anzutreffen ist, während die Spermatogonien (b) garnicht homogenisiert, vielmehr den lebenden Zuständen vollkommen ähnlich erscheinen, trotzdem dass beide Kernarten an der 
Peripherie knapp nebeneinander liegen und so der Wirkung der Flüssigkeit in vollkommen gleicher Weise ausgesetzt waren. Zweitens sind in dieser Abbildung drei verschiedene Bilder der "Spermatocyten" zu sehen (a. c. d.) welche ein und dasselbe Kernstadium repräsentieren. a. zeigt in einer dem Zentrum näher gelegenen Hälfte die sternförmigen bizarren Formationen der zentralen Wirkung, während ihre andere Hälfte noch ein wenig an die peripherische Wirkung erinnert, c. lässt feine fadenförmige Formationen vermuten, in d. erscheinen die ganz an der Peripherie liegenden Kerne fast vollkommen homogen blos einige kleine Nukleolen in sich schliessend. Die Peripherie ist durch die Konturlinie gekennzeichnet.

Fig. 2 a. Sich zur Reifungsteilung anschickende Spermatogonie, daneben zum Vergleich eine ruhende (b) die anch im Schnitte an der Peripherie unmittelbar neben ihr lag, daher beide das Bild der peripherischen Wirkung zeigen.

Fig. 3. Dasselbe Stadium wie 2 a aus der 5.-6. Zellreihe. Die Hälfte des Kernes zeigt noch die peripherische Wirkung.

Fig. 4. Dasselbe Stadium bei rein zentraler Wirkung. Beachtenswert ist die Fülle des Kernes an der Peripherie (2a) und das Fehlen der Grundsubstanz bei der zentralen Wirkung (4). Beide Erscheinungen sind in Fig. 3 an einem Kern sichtbar.

Fig. 5 a u. b. Übereinander liegende Formationen. a. peripherwärts, b. zentralwärts liegend; 3.-4. Zellreihe. a. entspricht der Fig. 1 c. Beide zeigen kleine Pünktchen und lassen feine fadenförmige Formationen vermuten. b. zeigt schon den Anfang des Zusammenfliessens der Kernsubstanz an der Grenze der eigentlichen peripherischen Wirkung.

Fig. 6. Formationen aus der rein zentralen Wirkungsphäre; nur ein kleiner Teil des Kernes ist gezeichnet. Verschiedene mit Fortsätzen versehene sternförmige Gebilde; gänzliches Fehlen der Grundsubstanz.

Fig. 7-8. Aufeinander folgende Bilder nach Wirkung der Flemmingschen Flüssigkeit. 7 a. gehört zur dritten Zellenreihe. Die ersten zwei Zellreihen wie in Fig. 1 d zeigen vollkommen homogene Kerne. Auf a. folgt unmittelbar zentralwärts b. u. c., hierauf Fig. 8, welche schon ausgesprochene zentrale Wirkung zeigt. (Vergleiche Fig. 6.)

Fig. 9. Der "Synapsis" der Autoren entsprechendes Kernstadium. Die grössere Hälfte des Kernes zeigt noch die sternförmigen Formationen, während in der anderen Kernhälfte eine Andeutung der Fadenbildung erkennbar ist.

Fig. 10. Peripherische Wirkung. Erster Schritt zur Mitose. Vakuolenbildungen in den Karyosomen. (Nicht sicher ob zur Reduktionsmitose gehörend.)

Fig. 11. Aus der 3.-4. Zellreihe der peripherischen Wirkung. Schwer analysierbare Formation. Etwas deutlicher als in Wirklichkeit gezeichnet. 


\section{Tafel XXVIII.}

Prophasen der Reifungsteilungen, sogenannte "Spermatocyten" des Salamanders. nach Wirkung der Kalibichr.-Essigsäure. Vergleiche Taf. XXVII.

Fig. 1-3. Peripherische Wirkung der Kaliessigsäure. Ungemein feine Formationen.

Fig. 1u.2. Zeigen klar den Charakter der Formationen, in sehr kleinen Kernstïckchen.

Fig. 3. Schwer wiederzugebendes, etwas dickeres Segment eines Kernes. Die dichteren Teile wahrscheinlich die letzten Spuren der Karyosomen.

Fig. 4. Zentrale Wirkung der Kaliessigs. Dasselbe Stadium wie Fig. 1-3! Sternförmige Formationen. Vergleiche Taf. XXVII, Fig. 6-8.

Fig. 5 a. u. b. Sehr kleine Kernteile, a) aus der peripherischen, b) aus der zentralen Wirkungszone, demselben Kernstadium entsprechend!

Fig. 6u. 7. Peripherische Wirkung. Seltenere Bilder mit länglichen feinfädigen Formationen; alle sehr kleine Kernfragmente.

Fig. 8. Einige Formationen mit dickeren und dünneren Fadenbildungen, in a. dieselben gemischt nebeneinander. $12^{\circ} \%$ Kalibichr. $5^{\circ} \%$ Essigsäure. Unten die Fortsätze der Faden sichtbar.

Fig. 9. Dicke Fadenbildungen, gemischt mit feiner verteilten Teilen. $12^{0}, 0$ Kalibichr. $5^{\%}$ Essigsäure.

Fig. 10. Dicker und feiner Faden gemischt nebeneinander (wie Fig. 8 a).

Fig. 11. Ausgebildeter dicker Faden obne andere Formationen. Sämtliche Fäden zu ihrer Längsachse genau in senkrechter Richtung geschnitten wie es $X$ in Fig. 9 zeigt. Die Fädendurchschnitte sind nach ihrer Zahl and Grösse genaue Kopien des Präparates. 